Louisiana State University

LSU Digital Commons

Faculty Publications

Department of Biological Sciences

$12-1-2017$

\title{
The phylogeny of Heliconia (Heliconiaceae) and the evolution of floral presentation
}

\author{
William J.D. Iles \\ Department of Plant \& Microbial Biology \\ Chodon Sass \\ Department of Plant \& Microbial Biology \\ Laura Lagomarsino \\ Department of Plant \& Microbial Biology \\ Gracie Benson-Martin \\ Department of Plant \& Microbial Biology \\ Heather Driscoll \\ Department of Plant \& Microbial Biology
}

See next page for additional authors

Follow this and additional works at: https://digitalcommons.Isu.edu/biosci_pubs

\section{Recommended Citation}

Iles, W., Sass, C., Lagomarsino, L., Benson-Martin, G., Driscoll, H., \& Specht, C. (2017). The phylogeny of Heliconia (Heliconiaceae) and the evolution of floral presentation. Molecular Phylogenetics and Evolution, 117, 150-167. https://doi.org/10.1016/j.ympev.2016.12.001

This Article is brought to you for free and open access by the Department of Biological Sciences at LSU Digital Commons. It has been accepted for inclusion in Faculty Publications by an authorized administrator of LSU Digital Commons. For more information, please contact ir@lsu.edu. 


\section{Authors}

William J.D. Iles, Chodon Sass, Laura Lagomarsino, Gracie Benson-Martin, Heather Driscoll, and Chelsea D. Specht 


\title{
The phylogeny of Heliconia (Heliconiaceae) and the evolution of floral presentation
}

\author{
William J.D. Iles*, Chodon Sass, Laura Lagomarsino ${ }^{1,2}$, Gracie Benson-Martin ${ }^{3}$, Heather Driscoll ${ }^{4}$, \\ Chelsea D. Specht*
}

Department of Plant and Microbial Biology, Department of Integrative Biology and The University and Jepson Herbaria, University of California, Berkeley, Berkeley, CA 94720, USA

\section{A R T I C L E I N F O}

\section{Article history:}

Received 10 September 2016

Revised 29 November 2016

Accepted 1 December 2016

Available online 18 December 2016

\section{Keywords:}

Correlated evolution

Ensete oregonense

Evolutionary distinctiveness

In-solution sequence capture

Museum specimens

Taxonomic history

Threshold model

Zingiberales

\begin{abstract}
A B S T R A C T
Heliconia (Heliconiaceae, order Zingiberales) is among the showiest plants of the Neotropical rainforest and represent a spectacular co-evolutionary radiation with hummingbirds. Despite the attractiveness and ecological importance of many Heliconia, the genus has been the subject of limited molecular phylogenetic studies. We sample seven markers from the plastid and nuclear genomes for 202 samples of Heliconia. This represents ca. $75 \%$ of accepted species and includes coverage of all taxonomic subgenera and sections. We date this phylogeny using fossils associated with other families in the Zingiberales; in particular we review and evaluate the Eocene fossil Ensete oregonense. We use this dated phylogenetic framework to evaluate the evolution of two components of flower orientation that are hypothesized to be important for modulating pollinator discrimination and pollen placement: resupination and erect versus pendant inflorescence habit. Our phylogenetic results suggest that the monophyletic Melanesian subgenus Heliconiopsis and a small clade of Ecuadorian species are together the sister group to the rest of Heliconia. Extant diversity of Heliconia originated in the Late Eocene (39 Ma) with rapid diversification through the Early Miocene, making it the oldest known clade of hummingbird-pollinated plants. Most described subgenera and sections are not monophyletic, though closely related groups of species, often defined by shared geography, mirror earlier morphological cladistic analyses. Evaluation of changes in resupination and inflorescence habit suggests that these characters are more homoplasious than expected, and this largely explains the non-monophyly of previously circumscribed subgenera, which were based on these characters. We also find strong evidence for the correlated evolution of resupination and inflorescence habit. The correlated model suggests that the most recent common ancestor of all extant Heliconia had resupinate flowers and erect inflorescences. Finally, we note our nearly complete species sampling and dated phylogeny allow for an assessment of taxonomic history in terms of phylogenetic diversity. We find approximately half of the currently recognized species, corresponding to half of the phylogenetic diversity, have been described since 1975, highlighting the continued importance of basic taxonomic research and conservation initiatives to preserve both described and undiscovered species of Heliconia.
\end{abstract}

(c) 2016 Elsevier Inc. All rights reserved.

\footnotetext{
* Corresponding authors.

E-mail addresses: will.jd.iles@gmail.com (W.J.D. Iles),cdspecht@berkeley.edu (C.D. Specht).

${ }^{1}$ Current address: University of Missouri-St. Louis, Biology Department, One University Blvd., Research Building, St. Louis, MO 63121, USA

2 Current address: University of Gothenburg, Department of Biological and Environmental Sciences, Carl Skottsbergs gata 22B, P.O. Box 461, SE 405 30, Göteborg, Sweden.

${ }^{3}$ Current address: Crop Improvement and Genetics Research Unit, USDA-ARS WRRC, 800 Buchanan St., Albany, CA 94710, USA

${ }^{4}$ Current address: Vermont Genetics Network, Department of Biology, Norwich University, Northfield, VT 05663, USA.
}

\section{Introduction}

Heliconia $\mathrm{L}$. is a charismatic member of the lowland tropical rainforests of the Neotropics and Melanesia, easily recognized by banana-like leaves and inflorescences with large, showy bracts. Heliconia is the sole genus in Heliconiaceae (order Zingiberales) and comprises approximately 194 recognized species (Govaerts and Kress, 2016) and a number of undescribed species (ca. 25, C. D.S., unpublished data). Most species were described in the last quarter of the 20th Century, and many were the result of substantial taxonomic research carried out by the late Lennart Andersson and W. John Kress in the 1980s and 1990s (Andersson, 1992, 
1985a, 1985b, 1981; Kress, 1990, 1984), which left only subgenus Griggsia as incompletely treated taxonomically, described partially in regional floras (Andersson, 1985b; Kress, 1984). Andersson and Kress also published cladistic morphological analyses which informed their infrageneric taxonomic systems (see Table 1; Andersson, 1992; Kress, 1984; Kress et al., 2004). Based on cladistic analyses, the genus was divided into five subgenera (Table 2), with three of these subgenera corresponding to taxa with putative synapomorphies involving flower orientation; either as sharing (1) twisting of the flower pedicel (resupination) or (2) whole inflorescence habit (erect versus pendant) (Table 2). Despite taxonomic and morphological interest in this genus and its important ecological presence in tropical forests, studies of the molecular diversity of Heliconia have been infrequent (but see: Isaza et al., 2012; Marouelli et al., 2010) or focused on population level processes (Côrtes et al., 2013; Stein et al., 2014; Suárez-Montes et al., 2011; Westerband and Horvitz, 2015). Bridging the gap between our knowledge of the morphological diversity in Heliconia and its molecular diversity is necessary for understanding the evolution of the genus and for characterizing co-evolution with other lineages.

As an ubiquitous member of Neotropical rainforests, Heliconia is involved in a number of co-evolutionary relationships: as prey items for herbivorous rolled-leaf beetles (McKenna and Farrell, 2006; Strong, 1982, 1977), as hosts for parasitic floral mites (Colwell and Naskrecki, 1999; Dobkin, 1990, 1985; Pessoa et al., 2015), and, perhaps most famously, with their co-adapted hummingbird pollinators in the Neotropics (Fig. 1) (Feinsinger, 1978; McDade, 1983; Stiles, 1979; Taylor and White, 2007; Temeles et al., 2016, 2000; Temeles and Kress, 2003). At local scales, hummingbirds and Heliconia partition their mutual resources (nectar and pollination services) through co-adapted changes involving the length and curvature of the hummingbird bill and the Heliconia flower. This may involve pollination by different species of hummingbirds (Taylor and White, 2007) or even differential morphology and food plant preferences between the sexes of a single hummingbird species (Temeles et al., 2016, 2000; Temeles and Kress, 2003). The Heliconia species involved are often closely related species pairs (e.g., $H$. bihai and $H$. caribaea [Temeles and Kress, 2003] or $H$. beckneri and $H$. tortuosa [Taylor and White, 2007]), and partitioning pollinators and changing the location of pollen placement on a pollinator via differences in flower size, shape, and orientation serves to limit inter-species pollen interference (Galen and Gregory, 1989). Thus, such floral and inflorescence characters act as a pre-pollination reproductive barrier before prezygotic incompatibility barriers are established (Kress, 1983), and are likely closely connected to speciation in this genus.

While flower length and curvature are the primary means by which Heliconia modulates pollinator visitation preferences and behavior, changes in flower orientation via resupination and inflorescence habit should also impact pollination through both pollen placement and pollinator behavior (e.g., favoring perching versus hovering by hummingbird visitors; Taylor and White, 2007). These aspects of Heliconia reproductive morphology have been used to define subgenera (Table 2). If the current classification of Heliconia reflects evolutionary relationships, changes in these characters are expected to be relatively rare and their character states phylogenetically consistent (non-homoplasious) compared with changes in flower length and curvature. However, morphological analyses suggested that resupination and inflorescence habit may be more homoplasious than indicated by current classification (Kress, 1984). As a result, changes in flower orientation as either a consequence or driving force of diversification in Heliconia may be more common than previously considered.

The goal of this study is to infer a species level phylogeny for the genus, sampling from all subgenera and sections of Heliconia. This
Table 1

Comparison of recent and informal infrageneric classifications for Heliconia. Species composition is generally similar but not necessarily identical between the sections of these two systems (this disparity is most pronounced in the sections of subgenus Griggsia).

\begin{tabular}{ll}
\hline Andersson, 1992 & Kress et al., 2004 (with updates by C.D.S.) \\
\hline subg. Heliconia & subg. Heliconia \\
sect. Episcopales (Griggs) L. & sect. Episcopales (Griggs) L.Andersson \\
$\quad$ Andersson & sect. Heliconia \\
sect. Heliconia & sect. Tenebria L.Andersson \\
sect. Tenebria L.Andersson & sect. Tortex \\
sect. Tortex & sect. Complanatae Kress, ined. \\
& sect. Farinosae Kress, ined. \\
subg. Heliconiopsis (Miq.) Kress & subg. Heliconiopsis (Miq.) Kress \\
subg. Stenochlamys Baker & subg. Stenochlamys Baker \\
sect. Cannastrum L.Andersson & sect. Cannastrum L.Andersson \\
sect. Lanea L.Andersson & sect. Lanea L.Andersson \\
sect. Lasia L.Andersson & sect. Lasia L.Andersson \\
sect. Proximochlamys L.Andersson & sect. Proximochlamys L.Andersson \\
sect. Stenochlamys & sect. Stenochlamys \\
sect. Zingiberastrum L.Andersson & sect. Zingiberastrum L.Andersson \\
subg. Taeniostrobus (Kuntze) Griggs & subg. Taeniostrobus (Kuntze) Griggs \\
subg. Griggsia L.Andersson & subg. Griggsia L.Andersson \\
H. griggsiana group & sect. Griggsia ined. \\
H. pogonantha group & sect. Barbatae Kress, ined. \\
H. longa group & sect. Arcuatae Kress, ined. \\
H. platystachys group & sect. Longae Kress, ined. \\
H. rostrata group & sect. Pendulae Kress, ined. \\
H. trichocarpa group & sect. Rostratae Kress, ined. \\
H. obscura group & sect. Sigmoideae Kress, ined. \\
H. nutans group & sect. Obscurae Kress, ined. \\
& sect. Contortex Kress, ined. \\
& sect. Dromedarius Kress, ined. \\
& sect. Retiformes Kress, ined. \\
\hline & \\
& \\
&
\end{tabular}

Table 2

Reproductive characters, plant habit, and distribution for the subgenera of Heliconia (Andersson, 1992, 1985a; Kress, 1990). Plant habit in Heliconia is either banana-like (musoid) with large petiolate leaves comprising a prominent pseudostem, ginger-like (zingiberoid) with a pronounced aerial stem with relatively small leaves arising along it at regular intervals, or somewhat in-between these two extremes (cannoid).

\begin{tabular}{|c|c|c|c|}
\hline Subgenus & Reproductive characters & Plant habit & Distribution \\
\hline Heliconia & $\begin{array}{l}\text { Erect inflorescence, flowers } \\
\text { non-resupinate }^{a}\end{array}$ & Musoid & Neotropics \\
\hline Heliconiopsis & $\begin{array}{l}\text { Erect or pendant inflorescence, } \\
\text { non-resupinate }\end{array}$ & Musoid & Melanesia \\
\hline Stenochlamys & $\begin{array}{l}\text { Erect inflorescence, flowers } \\
\text { resupinate }\end{array}$ & $\begin{array}{l}\text { Musoid, } \\
\text { cannoid, } \\
\text { zingiberoid }\end{array}$ & Neotropics \\
\hline Taeniostrobus & $\begin{array}{l}\text { Erect inflorescence, flowers } \\
\text { resupinate or non-resupinate, } \\
\text { bracts overlapping }\end{array}$ & Musoid & Neotropics \\
\hline Griggsia & $\begin{array}{l}\text { Pendant inflorescence, non- } \\
\text { resupinate }\end{array}$ & Musoid & Neotropics \\
\hline
\end{tabular}

a Andersson (1992) considered Heliconia clinophila, $H$. gracilis, $H$. ignescens, and $H$. librata to be resupinate (which he nonetheless placed in subg. Heliconia); based on photographic evidence (e.g., Berry and Kress, 1991) and personal observations (C.D. S.) we here consider these species to be non-resupinate, in agreement with the rest of the subgenus.

allows us to evaluate infrageneric classifications and evolutionary history of characters described in previous morphological analyses (Andersson, 1992; Kress, 1984; Kress et al., 2004). The dense species sampling included in this analysis permits macroevolutionary hypothesis testing, particularly in regards to correlations between the evolution of resupination and inflorescence habit. Although our species level sampling is nearly complete, species boundaries in Heliconia are often unclear because of complex patterns of reproductive and vegetative traits, both within and between species (Andersson, 1992, 1985a, 1981; Kress, 1990, 1984). Comprehensive 
Erect \& Resupinate
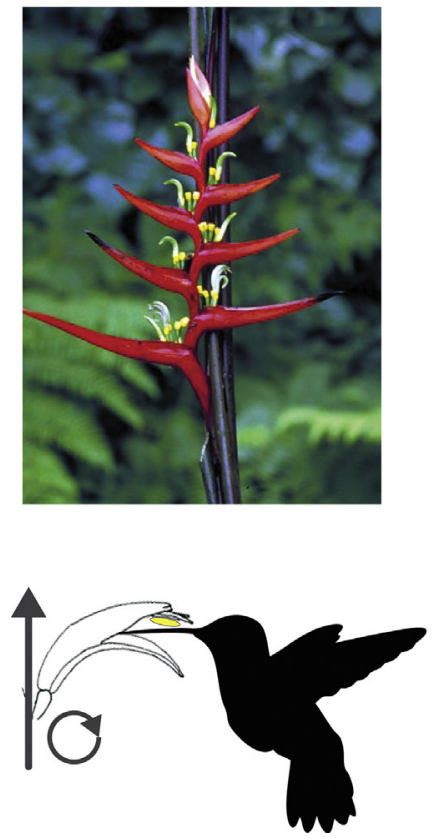

Erect \& Non-resupinate
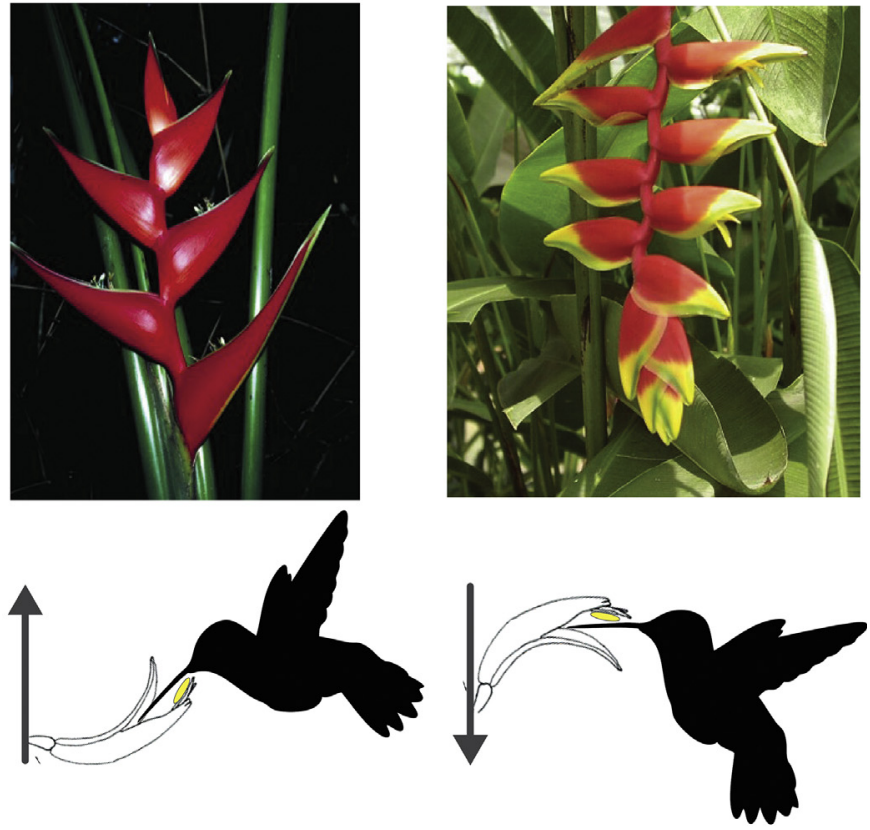

Pendant \& Non-resupinate

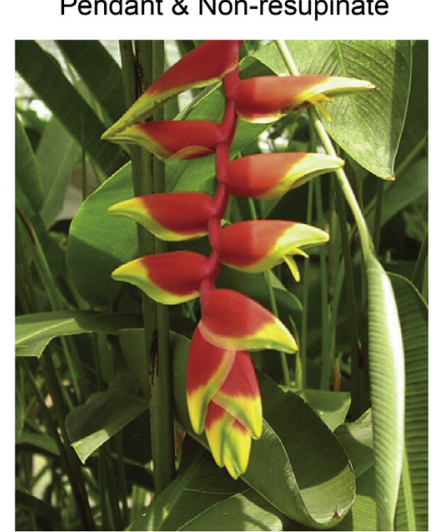

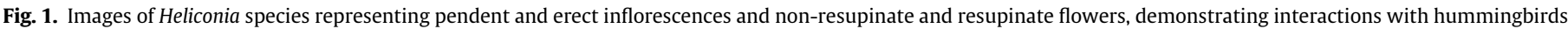

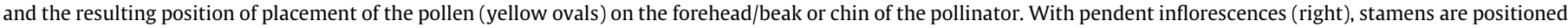

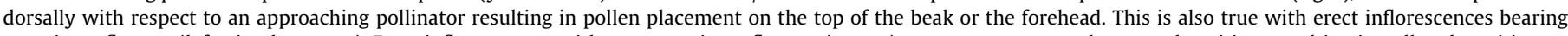

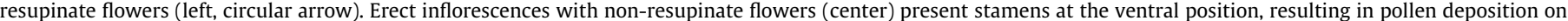

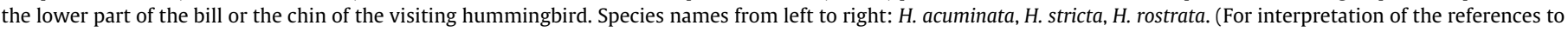
colour in this figure legend, the reader is referred to the web version of this article.)

population-level analysis of phylogenetic relationships in order to completely address species monophyly is beyond the scope of this project, and exemplars are used to represent most species. By focusing on macroevolutionary trends across a dense sampling of phylogenetic diversity, the problem with species boundaries should not affect our ability to understand the evolution of these reproductive traits.

\section{Material and methods}

\subsection{Taxonomic sampling}

Nomenclature generally follows Govaerts and Kress (2016) (for synonymies present in our sampling see Appendix A) and taxonomic circumscription primarily follows Andersson (1992, 1985a, 1985b, 1981) and Kress (1990, 1984). Names are not always consistently applied by the two authors; for example Andersson (1985a) considers Kress' (1984) Heliconia curtispatha and H. stilesii to be unwarranted segregates of $H$. longa, and considers Kress' $H$. sessilis to a be synonym of $H$. curtispatha sensu Andersson. Kress considers all these taxa to be distinct, with a close relationship between $H$. curtispatha sensu Kress and $H$. stilesii, but with $H$. sessilis distinct. Since the application of the name $H$. curtispatha is thus at odds, the species name in this analysis is followed by an ' $A$ ' for sensu Andersson or a ' $K$ ' for sensu Kress according to the original sample identification.

We obtained material from natural history collections (herbaria and botanical gardens) as well as targeted collecting in the wild (with vouchers deposited in natural history collections as indicated). Our strategy was to include samples from all 5 subgenera and all 23 sections identified by Kress et al. (2004) (see Table 1). In total, we include 202 samples that represent 152 of 194 accepted species sensu Govaerts and Kress (2016), one hybrid species, and five undetermined specimens. Seven of the samples represent type collections. We sampled one to six species from each of the remaining seven families of Zingiberales (Cannaceae, Costaceae, Lowiaceae, Marantaceae, Musaceae, Strelitziaceae, and Zingiberaceae) as outgroups. Appendix B includes voucher data for all samples.

\subsection{Genomic sampling}

For genomic sampling we selected the plastid markers trnL-F and trnL-rpl32, the nuclear ribosomal internal transcribed spacers 1 and 2 (ITS) and the external transcribed spacer (ETS), and introns from the putatively single copy nuclear genes calmodulin (CaM), glyceraldehyde 3-phosphate dehydrogenase (G3PDH), and phosphoribulokinase (PRK). We used the following primers for amplification and sequencing: 'e' and 'f from Taberlet et al. (1991) for trnL-F; 'trnL (UAG), and 'rpL32-F' from Shaw et al. (2007) for trnLrpl32, 'ITS5A' and 'ITS4' from Stanford et al. (2000) and White et al. (1990) for ITS, '5'-primer' and '18S-IGS' from Baldwin and Markos (1998) and Kay et al. (2005) for ETS, newly developed primers 'CaMH-F' (5'-CGGAGATGGTTAGATCCCTTC-3') and 'CaMH-R' (5'-TTCTCGCCGAGGTTGGTCAT-3') for CaM, 'Fwd-Primer' from Sass and Specht (2010) and a newly developed primer 'G3A-R' (5'-TCCCTCBGATTCCTC CCTG-3') for G3PDH, and newly developed primers 'PRK-F' (5'-CTTGACCCACCTGAGCTGATA-3') and 'PRK-R' (5'-TCTGTTGTGTCACCTCTCCA-3') for PRK. G3PDH exists as two copies in Heliconia that are easy to distinguish based on sequence dissimilarity; here, we considered only a single copy, which we abbreviate G3A. DNA extraction followed modified CTAB or SDS protocols (Doyle and Doyle, 1987; Edwards et al., 1991; Konieczny and Ausubel, 1993) and PCR and thermocycler conditions follow standard and optimized protocols (details available upon request). Sanger sequencing was carried out using standard protocols on an Applied Biosystems 3100 in the Plant \& Microbial Biology Department or a 3700 at the Evolutionary Genetics Laboratory 
(UC Berkeley, Berkeley, CA USA). Sanger sequence base calling and contig assembly were done in Sequencher version 4.7 (Gene Codes Corporation, Ann Arbor, MI USA, www.genecodes.com).

For many samples taken from herbarium specimens, as well as for several silica dried ingroup and outgroup specimens, one or more of the seven gene regions proved recalcitrant to PCR and Sanger sequencing; these were obtained with an in-solution capture approach using PCR generated probes (SCPP, Peñalba et al., 2014). DNA was extracted from samples taken from herbarium sheets using a modified CTAB protocol (Doyle and Doyle, 1987). During extraction and library preparation, steps were taken to limit contamination from outside sources and increase total DNA yield: (i) extractions were performed in a laminar flow hood in a dedicated clean room free from PCR amplicons and using previously unopened reagents and filter tips; (ii) centrifugation and cold incubation steps were lengthened; (iii) library preparation steps (Meyer and Kircher, 2010) were performed separately for herbarium sampled material and those of fresh or silica dried leaf tissue.

For in-solution capture, PCR probes for the seven gene regions were generated using several individuals spanning the Heliconia phylogeny (based on a preliminary Sanger sequence only tree). All PCR products were gel extracted with a QIAquick gel extraction kit (Qiagen, Hilden, Germany, www.qiagen.com) to ensure probe purity. Genomic DNA was prepared for hybridization and sequencing as in Meyer and Kircher (2010). Probe generation, hybridization, and elution followed Peñalba et al. (2014). We performed six captures corresponding to herbarium versus non-herbarium, plastid versus nuclear, and outgroup versus ingroup DNAs separately to limit capture competition between putatively difficult to capture and easy to capture DNA. In additional, all outgroups DNA was extracted from fresh or silica preserved (not herbarium) material. After capture, pools were subject to limited PCR enrichment, size verification with the Bioanalyzer DNA 1000 kit (Agilent Technologies, Santa Clara, CA USA, www.agilent.com), quantification by qPCR using KAPA Library Quantification kit (Kapa Biosystems, Wilmington, MA USA, www.kapabiosystems.com), and pooled based on qPCR, size, and proportional number of base pairs captured. The pool was sequenced on a MiSeq (Illumina, San Diego, CA USA, www.illumina.com) at the UC Davis Genome Center. After sequencing, reads were processed according to Sass et al. (2016) with the addition that reads were evaluated for ancient DNA degradation with mapDamage2.0 (Jónsson et al., 2013). Additionally, some outgroups were selected from the dataset of Sass et al. (2016). Sequence data from a putative hybrid taxon, Heliconia $\times$ rauliniana, was captured using the SCPP method from silica dried material and was readily phased into two distinct alleles for most of the non-plastid genes, which we label A and B indicating the two parental genomes. The final combined matrix is $78 \%$ complete, with gene specific completeness ranging from $56 \%$ to $90 \%$.

\subsection{Alignment and phylogenetic analysis}

Each genic region was manually aligned in PhyDE 0.9971 (Müller et al., 2010) using published protocols (Graham et al., 2000; Graham and Olmstead, 2000). Two sections of ITS and of ETS were not alignable for the outgroup taxa and so these sections were removed for the outgroups only; for ITS, these correspond to positions $372-583$ and $760-1026$ and for ETS, to positions 1-113 and 202-600 in their respective alignments. Final alignment lengths are as follows: ITS, 1259 bp; ETS, 947 bp; trnL-F, 1078 bp; trnL-rpl32, $1856 \mathrm{bp}$; CaM, $1680 \mathrm{bp}$; G3A, $1161 \mathrm{bp}$, and PRK, $1580 \mathrm{bp}$.

We used PartitionFinder 1.1.1 (Lanfear et al., 2012) to find the optimal partitioning scheme and model of sequence evolution for the concatenated data set. The seven loci correspond to base subsets that are clustered. We used the greedy clustering algorithm with all models considered (except those with a portion of invariant sites, see Yang, 2014) and branch lengths linked, and schemes were evaluated using the Bayesian information criterion (BIC). We repeated the procedure, but limited the models explored to only $\mathrm{GTR}+\Gamma$ for downstream use in RAxML (Stamatakis, 2014), which does not allow for simpler models.

Maximum likelihood (ML) phylogenetic analysis was conducted using RAxML version 8.2.8 (Stamatakis, 2014) hosted on the CIPRES Science Gateway server (Miller et al., 2010). We used the optimal partitioned data set selected by PartitionFinder for RAxML which has four subsets corresponding to ITS, ETS, plastid regions combined, and single copy nuclear regions combined. We used the $-\mathrm{f}$ a option to assess bootstrap support and full ML searches in a single run. For the full ML search, 12 replicates were evaluated under the GTR $+\Gamma_{4}$ model of sequence evolution; for the bootstrap analysis, 1008 replicates were evaluated under the GTRCAT 25 model of sequence evolution (Stamatakis, 2006) using the rapid bootstrap algorithm (Stamatakis et al., 2008). We also conducted a Bayesian analysis in MrBayes version 3.2.6 (Ronquist et al., 2012), also hosted on CIPRES. Here, we used the optimal partitioned data set selected by PartitionFinder considering all models, which corresponds to all genes having their own subset except CaM and $\mathrm{G} 3 \mathrm{~A}$, which were combined into a single subset. We implemented the partitioned analysis in MrBayes by allowing each partition its own mixed model (Ronquist and Huelsenbeck, 2003).We ran MrBayes with two independent analyses of four chains each for $5 \times 10^{7}$ generations sampling every $5 \times 10^{3}$ generations and used a burnin of $25 \%$ before downstream analysis. We ran all of these steps on both ingroup only and ingroup and outgroup data sets in order to explore the potentially stochastic influence of outgroups on ingroup relationships (Barrett et al., 2014; Graham et al., 2002; Graham and Iles, 2009).

Because of an unexpected placement for Heliconia subulata (see Phylogeny Results 3.2 and Fig. 2) we considered a single alternative constraint tree, in which members of subgenus Griggsia near $H$. subulata (subgenus Stenochlamys) are constrained to be monophyletic exclusive of $H$. subulata. We then re-evaluated the relationships of the small resulting polytomy using the -g option of RAxML. The original ML tree was then compared to this constraint tree using the approximately unbiased test (AU; Shimodaira, 2002) implemented in Consel version 0.1j (Shimodaira and Hasegawa, 2001). Individual linked loci (ITS\&ETS, trnL-F\&trnL-rpl32, CaM, G3A, and PRK) were also evaluated using RAxML. These individual loci trees were, in general, poorly resolved and topological relationships had limited support. Although there was some evidence of topological incongruence, we did not pursue coalescent methods or methods to detect hybridization due to the limited information content of these individual gene trees and large errors associated with their inference. Alignments and partitions are available from Figshare (doi: 10.6084/m9.figshare.4238951 and doi: 10.6084/ m9.figshare.4238954).

\subsection{Molecular dating}

\subsubsection{Fossil calibrations}

There are no Heliconiaceae fossils for which character data would enable us to reliably calibrate the ingroup. Accordingly, we use two calibration points referable to Zingiberales and a root calibration referable to monocots. Liliacidites sp. 'A' represents the oldest reliable monocot fossil (Doyle and Hickey, 1976; reviewed in Iles et al., 2015); here we use its youngest age estimate (Aptian-Albian boundary) as a soft maximum age on the root of our phylogeny. This is a conservative estimate as crown Zingiberales (i.e., the limit of our taxon sampling) are unlikely to be as old as the oldest recorded monocot fossil. We use the fossil Spirematospermum chandlerae E.M.Friis as a calibration on stem 
Subgenus Griggsia

Subgenus Heliconia

Subgenus Heliconiopsis

Subgenus Stenochlamys

Subgenus Taeniostrobus

Hybrids \& Undetermineds

Outgroups

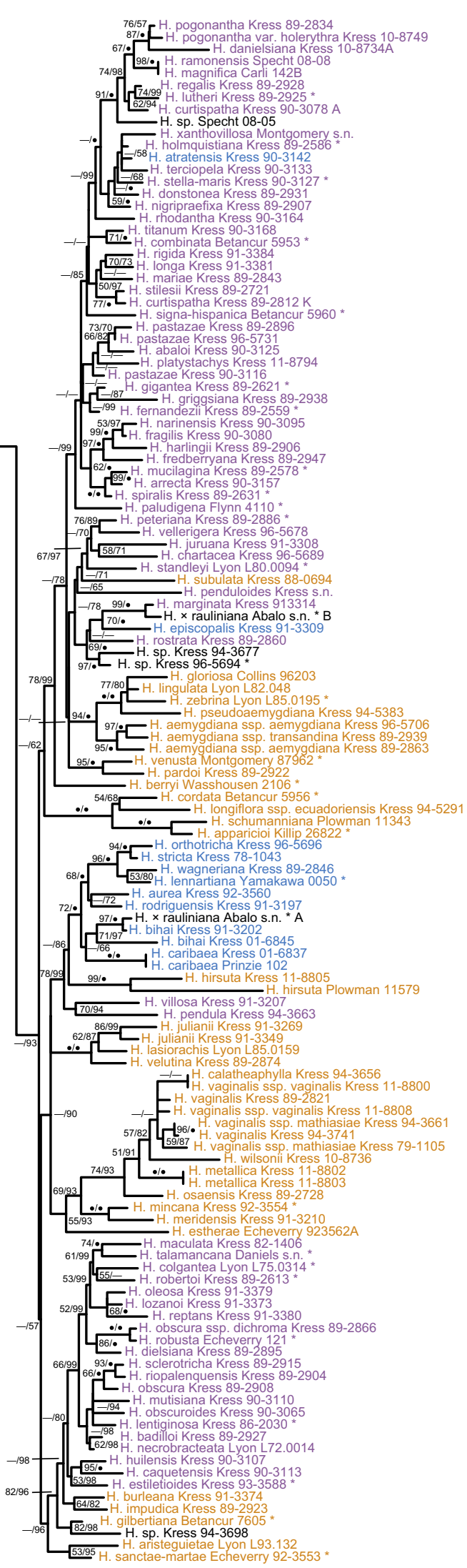

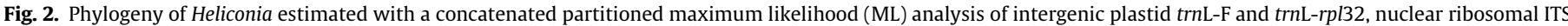

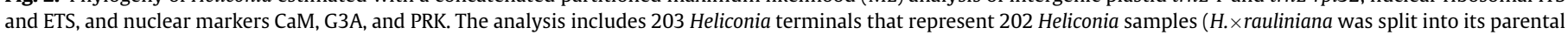

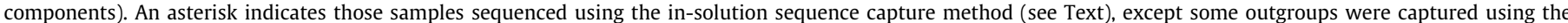

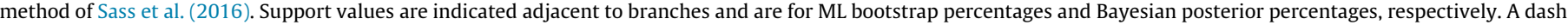

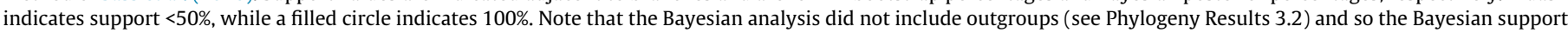

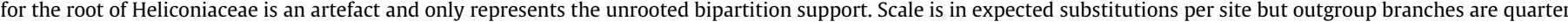
length (including the stem branch of Heliconiaceae). 
Zingiberaceae, following recent work suggesting that the fossil taxon belongs in Zingiberaceae (reviewed in: Iles et al., 2015 and Smith et al., 2013). Finally, we reviewed the taxonomic and geological context of Ensete oregonense Manchester \& W.J.Kress (holotype: UF 6621, Florida Museum of Natural History), described from a suite of chalcedony and permineralized seeds from the middle Eocene Nut Beds flora, Clarno Formation, Oregon, USA (Manchester and Kress, 1993). The fossil possesses apomorphic and quantitative characters (a wide, deep hilum with a hilar rim and consistent seed size) that associate it with Ensete Bruce ex Horan. to the exclusion of other Musaceae (Manchester and Kress, 1993); we therefore consider it suitable for calibrating the stem node of Ensete. The Nut Beds flora and the larger Clarno Formation have been extensively radiometrically dated, with most dates falling between $44-43 \mathrm{Ma}$, with one older result at $48.3 \mathrm{Ma}$ (reviewed in Hanson, 1996; Retallack et al., 2000). Some samples assignable to $E$. oregonense were also collected from near Wenatchee, Chelan Co., Washington, and initially attributed to the Swauk Formation (57-53 Ma) (reviewed in Manchester and Kress, 1993; fig. 8. Specimen OMSI-Pb 1061, however, their label is erroneous and the specimen should be UCMP 10689, pers. comm. Diane Erwin, U. California Museum of Paleontology, Berkeley, CA); however, more recent geologic maps suggest that this locality is more likely to be from the Roslyn/Chumstick Formation (46-43 Ma) (Cheney and Hayman, 2009), whose age is consistent with the age assigned to the Nut Beds flora. We thus discount the possible older dates for the Washington samples, and use the oldest date reported by B.D. Turrin in Manchester (1994) (i.e., $43.8 \mathrm{Ma}$ ) to calibrate E. oregonense.

\subsubsection{Dating analysis}

MCMCtree from PAML version 4.9a (Yang, 2007) was used to date the full ML tree with outgroups, following modification of the tree such that outgroups reflect hypothesized relationships based on more complete datasets (Sass et al., 2016). We used the approximate likelihood method where branch lengths are first estimated using ML, and the Markov chain Monte Carlo (MCMC) is performed on an approximation of the likelihood (Dos Reis and Yang, 2011). The $\mathrm{HKY}+\Gamma_{5}$ model of sequence evolution, which is the most complex model allowed using the approximate likelihood method, was used for tree building. While we initially tried using the optimal partitioning scheme, missing data resulted in problems during the ML branch length estimation stage; these were alleviated when we used a single combined subset. We used an autocorrelated model of rate evolution as a prior for the relaxed clock (Rannala and Yang, 2007). Several priors were initially estimated from exploratory analyses: the birth-death tree prior in MCMCtree and the gene substitution priors in the BASEML program from PAML (Yang, 2007). Calibration priors were implemented as uniform with soft bounds (Yang and Rannala, 2006). For calibration priors we considered the soft bounds to extend from the youngest possible age to $10 \mathrm{Myr}$ past the oldest possible age of the fossil in question; for Ensete oregonense this is 53.8-43.8 Ma and for Spirematospermum chandlerae, which is less precisely dated, this is 93.6-72.1 Ma. Liliacidites sp. 'A' only has a soft maximum bound, which is $113 \mathrm{Ma}$ (Fig. 3a). Because the calibration priors do not represent the actual time priors used during the MCMC run (Yang, 2014), we evaluated the actual time priors for suitability by running the analysis without sequence data (Fig. 3a). We ran the MCMC for $2.5 \times 10^{5}$ generations sampling every 5 generations and completed the analysis four times to ensure convergence.

\subsection{Floral evolution}

We gathered information on flower resupination and inflorescence habit (erect or pendant) from the literature (Andersson,
1992, 1985a, 1985b, 1981; Kress, 1990, 1984), with several exceptions enumerated here. Heliconia brenneri we consider to have an erect inflorescence as described in the original publication (Abalo, 1983) and based on personal observations (C.D.S., unpublished data) and not a pendant inflorescence as suggested by Andersson (1985a). We consider H. clinophila, H. gracilis, H. ignescens, and $H$. librata to be non-resupinate based on photographic evidence (Berry and Kress, 1991) and personal observations (C.D. S., unpublished data), not resupinate as suggested by Andersson (1992). All subsequent character evolution analyses were carried out on the MCMCtree dated phylogeny (Fig. 3) with outgroups and the putative hybrid, Heliconia $\times$ rauliniana, trimmed prior to analysis. We tested for correlated evolution using a Bayesian extension of Pagel (1994) as implemented in the Discrete function in BayesTraits version 2.0 (Barker and Pagel, 2005). This method compares a dependent (correlated) model of evolution between two binary characters with an independent (un-correlated) model of evolution. We use the log-Bayes factor (BF) to compare the independent and dependent models of evolution. The model marginal likelihoods were estimated using the stepping stone method with 100 'stones' and $1.0 \times 10^{5}$ generations per stone. The MCMC analysis was run for $5 \times 10^{6}$ generations and sampled every $5 \times 10^{3}$ generations; burn-in was set at $5 \times 10^{4}$ generations. The Bayesian version allows us to enforce bounds via priors on poorly estimated rate parameters: for the Heliconia dataset, these are transitions in the dependent model involving the resupinate and pendant character state combination, which does not exist among living species (Table 2). We evaluated a number of priors: a uniform prior of $0-$ 100 on rates, followed by exponential distribution priors with means of $10,1,0.1$, and 0.01 ( $\lambda=0.1,1,10$, and 100 , respectively). Transitions involving pendant and resupinate were variable among these prior options and did not converge, except for the exponential prior with 0.1 mean (Table 3 ). This process of prior evaluation was repeated for the independent model as well, in which case parameter estimates were stable and converged regardless of prior used (this is not surprising as all character states in the independent model are well represented in sampled species). In order to visualize ancestral states and obtain numbers of transitions between characters states, we used stochastic mapping (Huelsenbeck et al., 2003) using the estimated parameters of the $\mathrm{Q}$ matrix from the BayesTraits analysis as inputs. Stochastic mapping was performed in the $R$ package Phytools version $0.5-38$ (Revell, 2012) using a modified make.simmap function to allow for missing character states in the species data. We simulated 1000 mappings to approximate the posterior distribution.

Pagel's (1994) method of correlated evolution has recently been critiqued on the grounds that it produces spurious significant results under some conditions, such as when there is a single instance of two co-varying traits on the tree (Maddison and FitzJohn, 2015). Although Maddison and FitzJohn (2015) do not offer a definitive solution to this problem, they suggest use of the threshold model (Felsenstein, 2012, 2005; Wright, 1934) might side-step some of these issues. In this model, the discrete characters change when an unobserved quantitative trait (called a liability) crosses a threshold value. Felsenstein (2012, 2005) models the evolution of the liability with Brownian motion, for binary traits thresholds are set to 0 and variances to 1 . The model can be extended to multiple traits where correlations can then be calculated between the liabilities. We use the Bayesian implementation of the threshold model implemented in the $\mathrm{R}$ package Phytools as it automatically provides an indicator of uncertainty through the posterior distribution (Revell, 2014). The threshBayes function was used with $1.0 \times 10^{8}$ generations, sampling every $1.0 \times 10^{4}$.

All manual tree manipulations were performed in Mesquite version 3.03 (build 702) (Maddison and Maddison, 2009). 
A

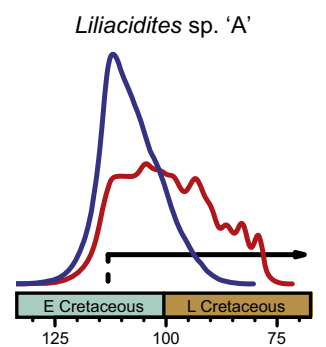

Ensete oregonense

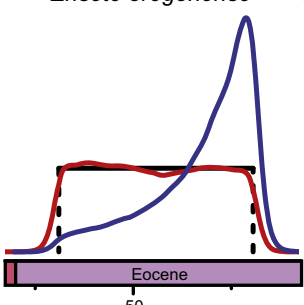

50

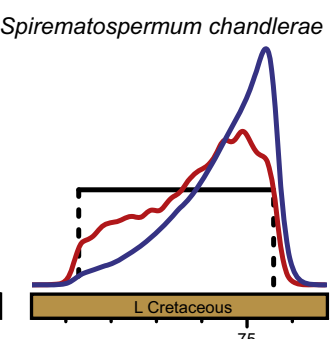

B
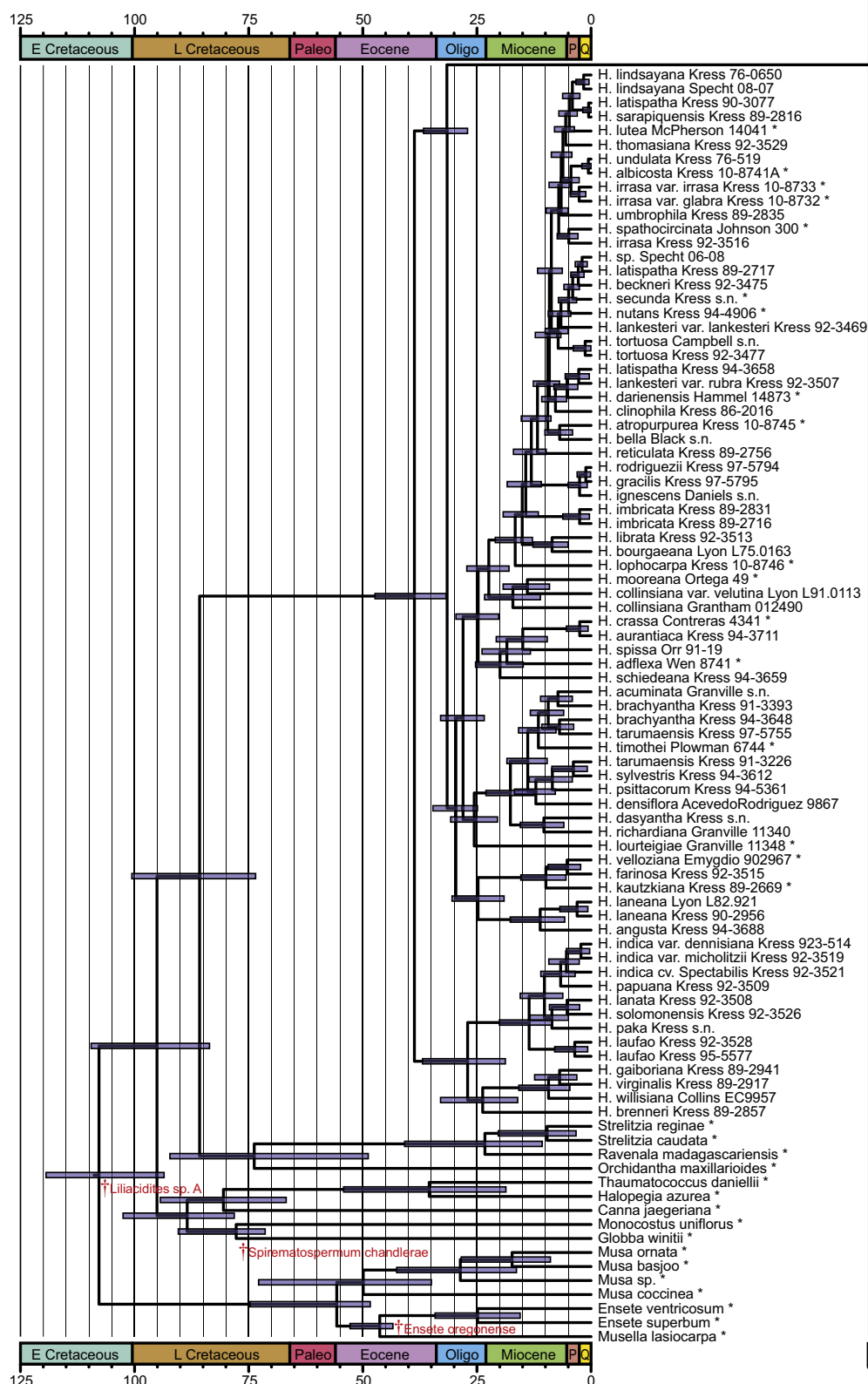

lindsayana Kress 76-0650 latispatha Kress 90-3077

undulata Kress 76-519

irrasa var. irrasa Kress 10-8733.

umbrophila Kress 89-2835

irrasa Kress $92-3516$

latispatha Kress 89-2717

beckneri Kress 92-3475

nutans Kress 94-4906.

92-3469 20 darienensis Hammel $14873^{\circ}$ atropurpurea Kress 10-8745

reticulata Kress 89-2756

gracilis Kress 97-579

imbricata Kress 89-2831

. librata Kress 92-3513

lophocarpa Kress $10-8746$

. colinsiana var. velutina Lyon L91.0113

. crassa Contreras $4341 *$
aurantiaca Kress $94-3711$

spissa Orr 91-19

acuminata Granvills 9405

brachyantha Kress $91-3393$

ourteigiae Granvile

rinosa Kress 92-3515

apuana Kress 92-350

laufao Kress 92-3528

gaiboriana Kress 89-2941

willisiana Collins ECO957

(relitzia reginae ${ }^{\star}$

125

100

75

25

3. Heliconia phylogeny through time. (a) Calibration prior time

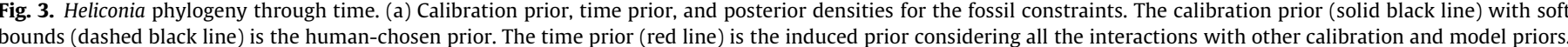

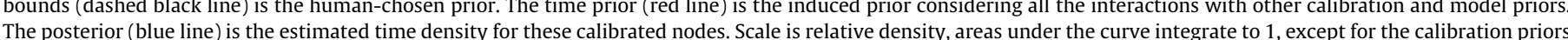

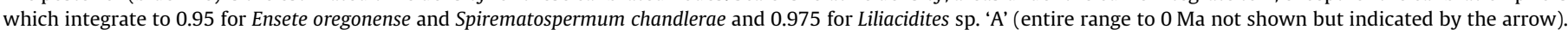

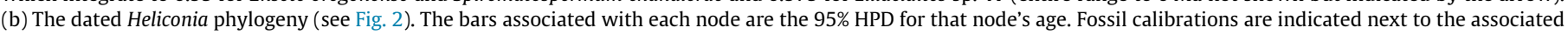

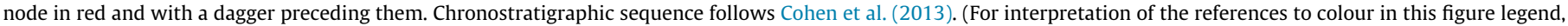
the reader is referred to the web version of this article.) 
Table 3

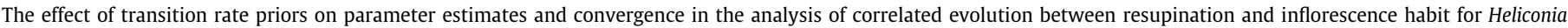

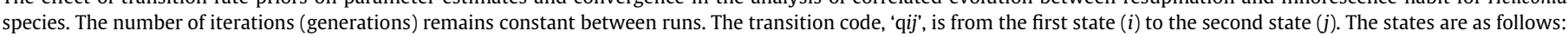

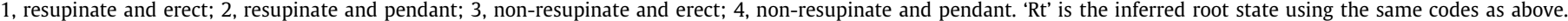
Parameter estimates are given as mean with $95 \%$ highest posterior density in parentheses.

\begin{tabular}{|c|c|c|c|c|c|}
\hline & Uniform 0-100 & Exponential 10 & Exponential 1 & Exponential 0.1 & Exponential 0.01 \\
\hline -Log-likelihood & $85.62(89.71-82.46)$ & $85.32(88.90-81.65)$ & $85.73(90.20-82.46)$ & $85.26(85.26-88.88)$ & $85.46(85.46-89.57)$ \\
\hline q12 & $0.008(0-0.077)^{\mathrm{a}}$ & $0.038(0-0.13)^{\mathrm{a}}$ & $0.020(0-0.060)^{\mathrm{a}}$ & $0.008(0-0.017)$ & $0.086(0-0.26)^{\mathrm{a}}$ \\
\hline q13 & $0.008(0-0.015)$ & $0.008(0-0.014)$ & $0.008(0-0.015)$ & $0.008(0-0.015)$ & $0.008(0-0.015)$ \\
\hline q21 & $0.14(0.006-6.30)^{\mathrm{a}}$ & $5.20(0.009-11.88)^{a}$ & $1.35(0.007-3.154)^{a}$ & $0.15(0.002-0.36)$ & $10.01(3.92-13.92)^{\mathrm{a}}$ \\
\hline q24 & $0.24(0.032-3.54)^{\mathrm{a}}$ & $1.79(0.089-4.046)^{\mathrm{a}}$ & $0.92(0.092-2.11)^{\mathrm{a}}$ & $0.21(0.017-0.42)$ & $1.20(0-2.75)^{\mathrm{a}}$ \\
\hline q31 & $0.011(0-0.028)$ & $0.012(0-0.027)$ & $0.012(0-0.029)$ & $0.011(0-0.026)$ & $0.012(0-0.029)$ \\
\hline q34 & $0.012(0.002-0.026)$ & $0.012(0.002-0.024)$ & $0.013(0.003-0.026)$ & $0.012(0.002-0.023)$ & $0.013(0.002-0.025)$ \\
\hline q42 & $0.007(0-0.023)^{\mathrm{a}}$ & $0.006(0-0.015)^{\mathrm{a}}$ & $0.007(0-0.021)^{\mathrm{a}}$ & $0.004(0-0.010)$ & $0.004(0-0.010)$ \\
\hline $\mathrm{q} 43$ & $0.005(0-0.011)$ & $0.005(0-0.011)$ & $0.005(0.001-0.012)$ & $0.005(0-0.010)$ & $0.005(0-0.010)$ \\
\hline Rt 1 & $0.52(0-0.87)^{a}$ & $0.50(0-0.76)^{\mathrm{a}}$ & $0.54(0-0.89)^{\mathrm{a}}$ & $0.60(0-0.93)$ & $0.42(0-0.61)^{a}$ \\
\hline Rt 2 & $0.23(0-0.42)^{\mathrm{a}}$ & $0.26(0-0.45)^{\mathrm{a}}$ & $0.20(0-0.41)^{\mathrm{a}}$ & $0.15(0-0.39)$ & $0.34(0-0.47)^{\mathrm{a}}$ \\
\hline Rt 3 & $0.24(0-0.97)$ & $0.23(0-0.96)$ & $0.26(0-0.98)$ & $0.25(0-0.98)$ & $0.24(0-0.98)$ \\
\hline Rt 4 & $0.005(0-0.014)$ & $0.004(0-0.015)$ & $0.004(0-0.015)$ & $0.002(0-0.008)$ & $0.004(0-0.015)$ \\
\hline
\end{tabular}

a Estimated sample size $<200$, no evidence of proper convergence.

\subsection{Taxonomic and phylogenetic diversity}

To explore the relationship between the taxonomic history of Heliconia and its phylogenetic diversity we used the species specific equal splits metric of evolutionary distinctiveness (Redding and Mooers, 2006) implemented in the $\mathrm{R}$ package Picante (Kembel et al., 2010). This was calculated on a per year basis whenever new species were described using the dated phylogeny (Fig. 3) trimmed to the species diversity known for that year. In cases where a species was represented by more than one sample in our phylogeny we chose a single exemplar.

\section{Results}

\subsection{In-solution sequence capture}

Sequence capture using PCR-generated probes worked effectively for all ingroup samples. All genes were captured for all individuals, although coverage varied. Samples with very low input DNA and all outgroup samples had the lowest average coverage, especially in low copy nuclear intronic DNA regions (Supplemental Fig. S1a-d). One herbarium specimen from 1923 had coverage comparable to silica dried specimens, although a second specimen from 1929 had very low input DNA and therefore coverage was very low, indicating that age of the herbarium specimen might not be as important as the pressing, drying, and storage conditions that might cause variability in DNA yield from extractions. Despite variable coverage in low copy nuclear intronic regions, input quantities of less than $1 \mathrm{ng}$ of DNA resulted in coverage of plastid and nuclear ribosomal DNA greater than 20X. DNA damage as measured by $3^{\prime} \mathrm{G}$ to $\mathrm{A}$ and $5^{\prime} \mathrm{C}$ to $\mathrm{T}$ conversion in DNA extracted from herbarium specimens was not different from frequencies found for DNA extracted from silica-dried tissue.

\subsection{Phylogeny}

The ML phylogeny is characterized by short and poorly supported internal branches along the Heliconia backbone (Fig. 2, Supplemental nwk file 1). Subgenus Heliconiopsis, comprising the geographically disjunct Old World Melanesian species, is monophyletic and is the sister group to a small clade of Ecuadorian species; together these are sister to the rest of the family (Fig. 2). All previously defined subgenera for Neotropical species (Stenochlamys, Heliconia, Griggsia, and Taeniostrobus) are not monophyletic, although groups of species that were placed in the same subgenus are often clustered together with high support (Fig. 2). Interest- ingly, these smaller groups often represent species that had been placed in the same taxonomic section, largely based upon biogeographic affinities (data not shown). The placement of samples sequenced using SCPP (indicated by an asterisk in Fig. 2) accords with their taxonomic position. Likewise the phased parental components of the hybrid, Heliconia $\times$ rauliniana, were also correctly identified (i.e., $H$. bihai and $H$. marginata) using this method (Fig. 2). The ingroup-only ML phylogeny shows similar relationships and support values, but some backbone branches had higher support when outgroup taxa were excluded (Supplemental nwk file 2). The Bayesian analysis that included outgroups failed to converge; despite this, general relationships, including the root for Heliconiaceae, remain the same as found in the ML tree including outgroups (Supplemental nwk file 3). These also mirrored the Bayesian ingroup phylogeny, which showed appropriate estimated sample size statistics (i.e., >200) and similar log-likelihood scores between the two runs (Fig. 2, Supplemental nwk file 4). However, the average standard deviation of split frequencies remained between 0.03 and 0.04 for the last $2 \times 10^{7}$ generations. The constrained tree (Supplemental nwk file 5) differed significantly from the unconstrained tree in the AU test, and is not considered further (p-value <0.05).

\subsection{Dated phylogeny}

The calibration priors impose similar time priors indicating that prior interactions of the whole model are not inducing an unreasonable set of time priors (Fig. 3a). Replicated MCMC runs indicated appropriate convergence. The dated phylogeny (Fig. 3b, Supplemental nwk file 6) suggests that Heliconiaceae split from other Zingiberales during the Late Cretaceous (86 Ma, 101$73 \mathrm{Ma}$; mean, 95\% highest posterior density [HPD]) and that current biodiversity of Heliconia originated in the Eocene to early Oligocene (39 Ma, 47-32 Ma; mean, 95\% HPD) followed by an initially rapid diversification that subsequently slowed down by the Miocene (Fig. 3b).

\subsection{Floral evolution}

We find very strong evidence of correlated evolution between resupination and inflorescence habit $(\mathrm{BF}=27)$ using the correlation test of Pagel (1994). Ancestral state reconstruction using the correlated model is shown in Fig. 4b. Resupinate flowers on an erect inflorescence is the most likely ancestral state combination for Heliconia. Pendant inflorescences with non-resupinate flowers evolved convergently multiple times ( $c a .13$ times), from either 
A
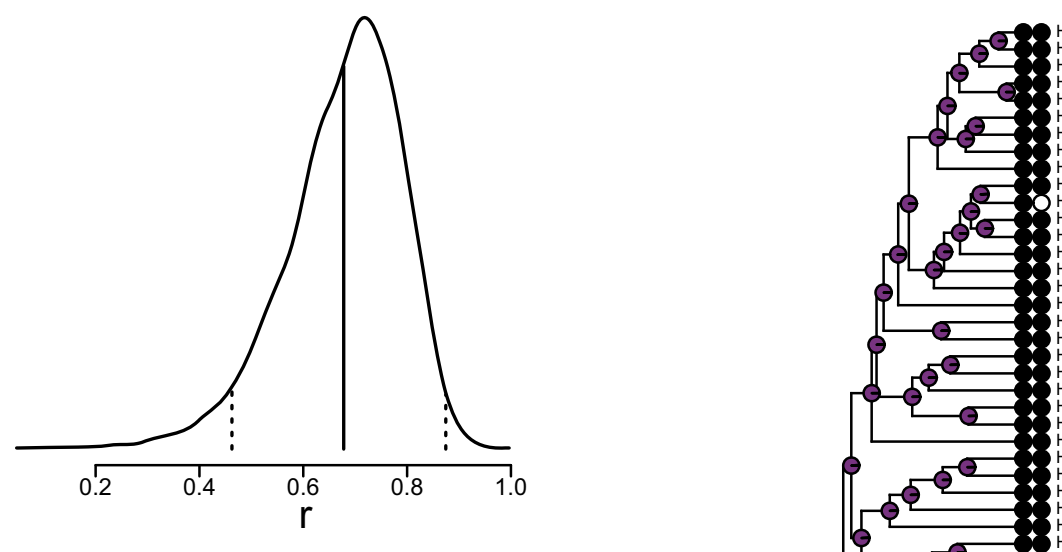

. pogonantha var. holerythra Kress 10-8749 pogonantha Kress 89-2834 danielsiana Kress 10-8734 magnifica Carli $142 B$
ramonensis Specht $08-08$
lutheri Kress $89-2925^{\star}$ regalis Kress 89-2928 curtispatha Kress 90-3078 A (erciopela Kress 90-3133 holmquistiana Kress 892586 * xanthovillosa Montgomery s.n. . igripraefixa Kress 89-2907 rhodantha Kress 90-3164 combinata Betancur 5953 . longa Kress 91-3381 rigida Kress 91-3384 mariae Kress 89-2843 curtispatha Kress 89-2812 K . pastazae Kress 96-5731 pastazae Kress 89-2896 abaloi Kress $90-3125$
platystachys Kress $11-8794$ platystachys Kress $11-8794$
pastazae Kress $90-3116$ griggsiana Kress 89-2938 gigantea Kress 89-2621* rnandezii Kress 89-2559 agilis Kress 90-3080 . harlingii Kress 89-2906
fredberryana Kress 89-2947 arrecta Kress 90-3157

B Internal nodes Tip nodes Resup. \& erect $\mathrm{L}=$ Resup. $\mathrm{R}=$ Inflor. habit Non-resup. \& erect Non-resup. \& pendant Resup. \& pendant

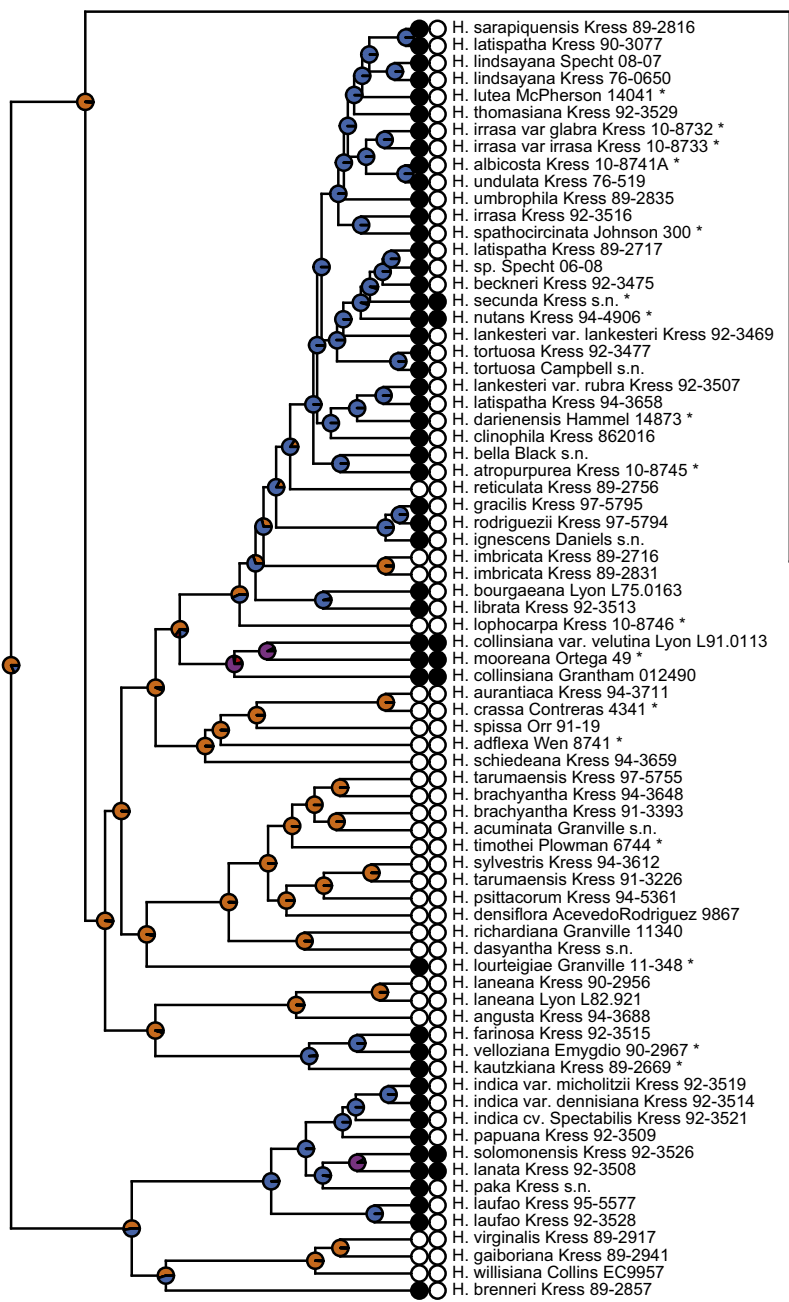

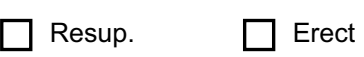

Non-resup.
Pendant 
non-resupinate and erect (ca. 4 times) or resupinate and pendant (ca. 9 times) character state combinations (Fig. 4b, Supplemental File 1). The threshold model also finds strong evidence for correlation between the underlying liabilities (Fig. 4a, $r=0.68,0.46-0.87$; mean, 95\% HPD). The root ancestral liability for inflorescence habit is $5.2(0.5-9.5$ 95\% HPD) standard deviations lower than that for resupination.

\subsection{Taxonomic and phylogenetic diversity}

Approximately half of the known species (Fig. 5) and half the cumulative phylogenetic diversity (Fig. 6) have been described since 1975 , this includes many species with individually high evolutionary distinctiveness scores (Fig. 6).

\section{Discussion}

The phylogeny and character evolution of Heliconia suggest a rapid and morphologically complex radiation starting in the Eocene within the Neotropics (Fig. 3). Although the backbone of Heliconia remains largely unresolved, strongly supported subclades occur throughout the tree (Fig. 2), many of them with a mix of resupination and inflorescence habit character states (Fig. 4). As a result, any resolved and well-supported phylogeny will be marked by substantial plesiomorphy and homoplasy for these reproductive characters. The evolution of resupination and inflorescence habit are strongly correlated $(r=0.64$, Fig. $4 a)$, consistent with the hypothesis that these aspects of flower orientation are influenced by selection by hummingbirds. The correlated model also suggests that resupinate flowers on an erect inflorescence is the ancestral state combination, and that non-resupinate flowers on either erect or pendant inflorescences are derived states (Fig. 4). In addition, our in-solution sequence capture proved effective at recovering sequence data from otherwise recalcitrant specimens, including herbarium specimens (Fig. 2, Suppl. Fig. S1).

\subsection{Species, classification, and phylogeny}

The phylogeny of Heliconia is characterized by very short backbone branches that lack statistical support (Fig. 2). However, many shallow branches are well supported, allowing us to suggest sets of relationships that can inform species boundaries and infrageneric taxonomy.

Infrageneric taxa of Heliconia frequently cluster together within the phylogeny, but are only rarely completely monophyletic. Only the subgenus Heliconiopsis, which is geographically disjunct in the islands of Melanesia, is monophyletic; the other subgenera are all non-monophyletic. The non-monophyly of subgenus Stenochlamys, which is defined in part by resupinate flowers borne on erect inflorescences (Andersson, 1985a), can largely be explained by the plesiomorphic nature of this character state combination (see Fig. 4). Similarly, the polyphyly of the other Neotropical subgenera, especially the large subgenera Heliconia and Griggsia, can be explained by the convergence of other combinations of the traits we examined; this includes Heliconia with erect inflorescences and nonresupinate flowers, and Griggsia with pendant inflorescences and non-resupinate flowers. Early morphological analyses predicted this result by suggesting three independent origins of pendant habit among Central American species (Kress, 1984).

While the subgenera of Heliconia were not found to represent lineages, many of the sections were found to be monophyletic or nearly so. For example, subgenus Griggsia sections Pendulae and Barbatae are each largely monophyletic, consistent with a previous morphological analysis (Andersson, 1992); these subclades could be considered subgenera in an updated classification once the phy- logeny is more completely resolved. Additional sections are found to be nearly-monophyletic including sections Lasia, Lanae, Cannastrum, and Zingiberastrum in subgenus Stenochlamys, and sections Farinosae and Tortex in subgenus Heliconia, among others. Interestingly, the two species placed in Griggsia section Contortex (Heliconia nutans and $H$. secunda) are resolved in a clade comprising members of subgenus Heliconia section Tortex, supporting observations by both Andersson (1985b) and Kress (1984) that these taxa appear affiliated to section Tortex, despite their pendant inflorescences that placed them taxonomically within subgenus Griggsia in the traditional classification scheme. The monophyly or near monophyly of many of these sections largely mirrors biogeography; for example, Heliconia sections Heliconia, Zingiberastrum, and Tortex; Stenochlamys sections Lanea and Stenochlamys; Griggsia section Sigmoidea among others. This indicates that there is a trend for regional diversification with little subsequent dispersal, and that biogeography should inform future classifications schemes, as is currently is this case with the monophyletic subgenus Heliconiopsis. Further, we provide strong evidence for the convergent nature of floral resupination and inflorescence habit, suggesting that while these traits cannot be used to define monophyletic taxa in classification, their evolution is incredibly dynamic, and likely driven by selection by hummingbird pollinators.

The short internal branches of the phylogeny of Heliconia suggest that methods that incorporate models of incomplete lineage sorting are appropriate for this group. Further supporting the use of these methods, we find that only $46 \%$ of 28 species (according to Govaerts and Kress, 2016; Fig. 2) with multiple samples are monophyletic and we detect some instances of inter-gene incongruence. These results are not necessarily surprising as incomplete lineage sorting is expected to produce conflicts between species and gene trees and among gene trees (Maddison, 1997; Rieseberg and Brouillet, 1994). Methods that account for this biological process, such as $*$ BEAST or ASTRAL (Heled and Drummond, 2010; Mirarab et al., 2014) should be applied to this group in the future. However, the application of these methods was not possible in this study due to a limited number of loci and few samples per species as well as the lack of resolution recovered in individual gene trees. In addition to biological causes, species non-monophyly can also result from taxonomic or phylogenetic inference error. Given the complex set of patterns displayed by morphological characters in Heliconia (Andersson, 1992, 1985a, 1985b, 1981; Kress, 1990, 1984), the lack of recent revisions for newly described species (Fig. 5), and only partial coverage of subgenus Griggsia (Andersson, 1985b; Kress, 1984), taxonomic error may be the cause of some of the species nonmonophyly seen in our phylogeny. Biological, taxonomic, and phylogenetic inference issues are amenable to resolution with greater sampling of individuals within putative species-complexes and increased sequence data for these individuals (e.g., Huelsenbeck et al., 2011; Yang and Rannala, 2014).

\subsection{Flower orientation and character evolution}

Results from Pagel's test (1994) and from Felsenstein's threshold model $(2012,2005)$ provide strong evidence for the correlated evolution of resupination and inflorescence habit in Heliconia (Fig. 4). In living species, pendant inflorescences always have non-resupinate flowers, while species with erect inflorescences may have either resupinate or non-resupinate flowers. A consequence of using the correlated evolution model (Fig. 4) is the ephemeral existence ( $<2 \%$ of total tree time, Supplemental File 1 ) of a resupinate and pendant character state combination, which is not observed in living species. Despite the short time that is spent in this combination of character states, twice as many origins of the non-resupinate and pendant combination originate through 


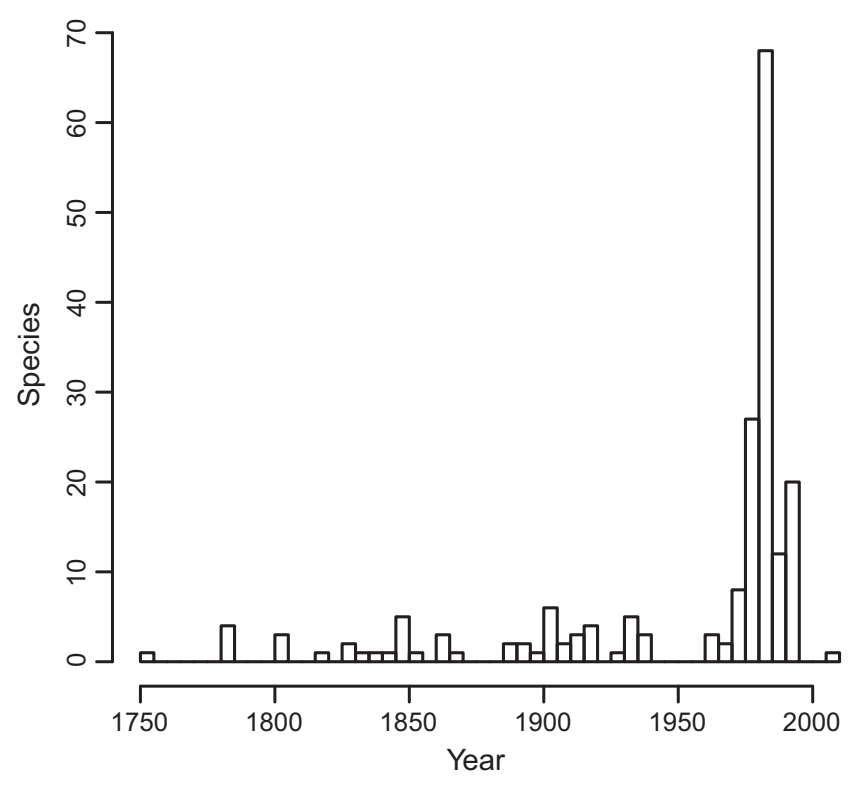

Fig. 5. Histogram of the publication date for currently accepted Heliconia species names. Accepted species names are according to Govaerts and Kress (2016) and publication date corresponds to the date of publication for the species name (or its basionym where applicable).

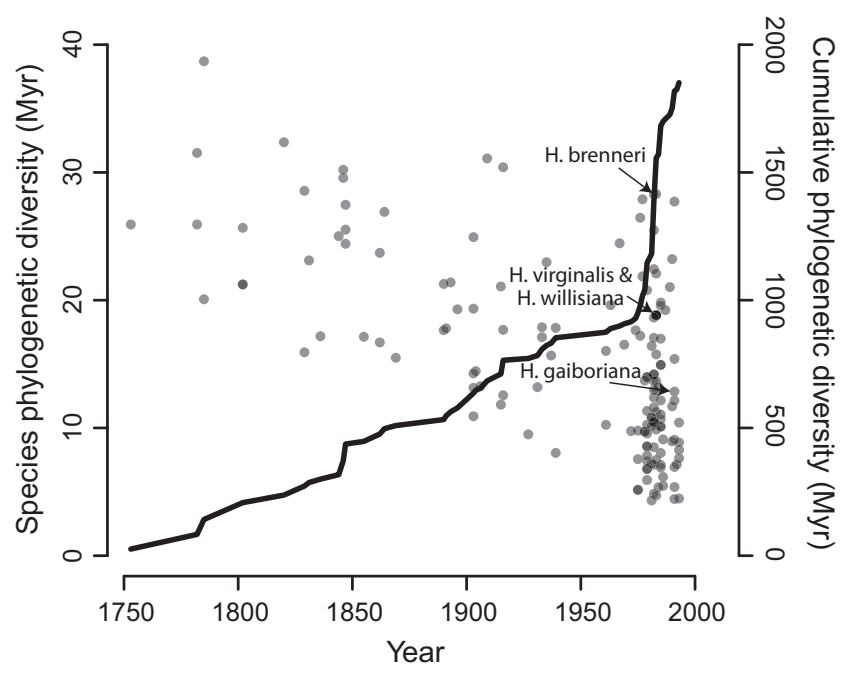

Fig. 6. Taxonomic history of Heliconia and its relation to phylogenetic diversity. Points (left-hand scale) correspond to species specific phylogenetic diversity calculated using the equal splits metric of evolutionary distinctiveness. The line (right-hand) corresponds to the cumulative phylogenetic diversity which is simply tree length trimmed to the species known for that year. Four species that belong to the Ecuadorian clade are highlighted (see Conclusion 5).

this hypothetical intermediary than through non-resupinate and erect (which accounts for $34 \%$ of total tree time, Supplemental File 1). This appears to be a function of the relatively high transition rates entering and exiting this character state combination (i.e., q12, q21, q24 in Table 3), despite efforts to constrain these rates through priors (note that the prior we use, exponential 0.1, gives lower rate estimates than the other priors, see Table 3). Given these high rates, it is tempting to interpret transitions of this type as representing a more-or-less simultaneous change from resupinate and erect to non-resupinate and pendant, although technically this transition is not allowed by the model. An alternative to trying to control the rates involved in unobserved character state combinations is to simply remove them from the model completely (Beaulieu and Donoghue, 2013). We do not attempt that here because it makes interpreting the result of Pagel's test difficult, and, unlike in some scenarios, there is nothing intrinsically implausible about a resupinate and pendant inflorescence.

Given the spatial and temporal separation in the development of whole inflorescence morphology and individual pedicels, it seems that correlations that arise between these two characters are unlikely to result from developmental constraints (Specht and Howarth, 2015) and are more likely indicative of a response to pollinator-mediated selection pressure. In our framework, we consider changes in flower orientation through resupination and inflorescence habit to be the product of co-adaptation with hummingbirds as a result of resource partitioning by both parties (Stiles, 1979). However, co-evolutionary studies have focused on the effect of flower size and shape, not resupination or inflorescence habit (Taylor and White, 2007; Temeles et al., 2016, 2000; Temeles and Kress, 2003). It would be informative to study a system where closely related species of Heliconia differ in resupination or inflorescence habit, such as members of subgenus Griggsia section Contortex and subgenus Heliconia section Tortex, to see if similar levels of pollinator partitioning occur. Our focus has been on hummingbird pollinators, but we note that the Melanesian subgenus Heliconiopsis, that also contains a pendant lineage (Fig. 4), is bat pollinated (Kress, 1985). This appears to mimic the situation in the closely related Old World banana family (Musaceae, Zingiberales), which comprises species with erect and pendant inflorescences that are bat pollinated (Andersson, 1998).

In both Heliconia and Musaceae, species with pendant inflorescences comprise the largest species (overall above-ground body size) and species with the longest inflorescences (Andersson, 1998; C.D.S., W.J.D.I., unpublished data). For example, Heliconia gigantea has a $3 \mathrm{~m}$ long pendant inflorescence and a pseudostem (overlapping leaf petioles) $6.5 \mathrm{~m}$ tall (Kress et al., 1993). The evolution of pendant inflorescences may facilitate gigantism by lowering the plant's center of gravity, possibly creating a more biomechanically stable configuration. This is relevant in both Heliconia and Musaceae as all the mechanical support is born by the pseudostem and no secondary growth is possible in these overgrown monocotyledonous herbs. Alternatively, a pendant inflorescence likely has a lower construction cost due to a reduced need for structural elements, thereby reducing the marginal cost of each additional bract and facilitating the evolution of longer inflorescences in pendant species. A comparative study of both these closely related families together with the large erect inflorescences found in the woody (sensu Fitzjohn et al., 2014) Strelitziaceae (e.g., the Madagascan traveler's palm, Ravenala Adans.) would reveal the magnitude and extent of this possible association between pendant inflorescences and inflorescence length as well as overall plant size.

The period of rapid speciation in Heliconia during the Oligocene and early Miocene (Fig. 3) is co-incident with radiations in Heliconia's predators, the hispine rolled-leaf beetles (McKenna and Farrell, 2006) and in Heliconia's Neotropical pollinators, the hummingbirds (McGuire et al., 2014). This suggests that ancient codiversification between Heliconia and hummingbirds may have driven morphological diversification in Heliconia, and has likely continued to do so since then, just as it does in current ecosystems (Feinsinger, 1978; Stiles, 1979; Taylor and White, 2007; Temeles et al., 2016, 2000; Temeles and Kress, 2003). Dating analyses of extant hummingbirds suggest a much younger age-22 Ma-of Heliconia's obligate pollinators, the hummingbirds (McGuire et al., 2014). However, there is a substantial gap between Neotropical crown group hummingbirds and the only known stem fossil (Eurotrochilus inexpectatus Mayr, 2004), an Old World taxon from ca. $32 \mathrm{Ma}$ in Frauenweiler, Germany (Mayr, 2007, 2004). The age of this fossil overlaps with the HPD age estimate of crown group 
Heliconia. This suggests that Heliconia may have been one of the first clades to interact with the stem-group hummingbirds that dispersed to the New World and perhaps paved the way for a more expanded hummingbird-pollinated plant guild. The old age of Heliconia relative to other hummingbird-pollinated clades further supports the hypothesis that Heliconia underwent diffuse co-evolution with hummingbirds (sensu Tripp and McDade, 2013), bolstered by the correlated evolution of traits involved in precise pollen placement during this interaction. Hummingbird pollination in other taxa was likely facilitated by this pre-existing relationship, and explains the much younger crown ages inferred for other species-rich, largely hummingbird pollinated clades (e.g., Neotropical Campanulaceae-Lobelioideae at ca. $5 \mathrm{Ma}$ : Lagomarsino et al., 2016; Acanthaceae-Ruellia at ca. 9 Ma: Tripp and McDade, 2013; Gesneriaceae-Columneinae at 22.4 Ma: Roalson and Roberts, 2016; Passiflora supersection Tacsonia at ca. 8.4 Ma: Abrahamczyk et al., 2014; Bromeliaceae at 22.7 Ma: Givnish et al., 2014).

\subsection{Conclusion}

The spectacular radiation of Heliconia reveals that characters related to flower orientation evolve in a correlated fashion and are much more homoplasious than previously indicated by taxonomic subdivisions. Flower orientation is clearly important for precise pollen presentation, especially in large-bodied pollinators such as hummingbirds; this has direct implications for the evolution of reproductive isolation, and thus may be important in the speciation process in Heliconia. About half the species diversity in Heliconia has been discovered since 1975 (Fig. 5), which mirrors the large number of Amazonian tree species described in the second half of the 20th Century (ter Steege et al., 2016). Crucially, many of these newly described Heliconia species are phylogenetically distinct, adding substantial amounts of evolutionary history to Heliconia phylogeny (see right-hand Fig. 6). Perhaps the most phylogenetically important species described during this time include those Ecuadorian species that, along with the Melanesian Heliconiopsis, comprise the sister group to all other Heliconia species (see lefthand Fig. 6). This may indicate that there is unsampled biodiversity and that continued taxonomic exploration is of ongoing importance for understanding extant diversity and setting conservation priorities for Heliconia (EDGE, 2016; Isaac et al., 2007).

\section{Acknowledgements}

We thank our reviewers T. Givnish and L. McDade for insightful comments and T.G. in particular for suggesting that lowered construction costs in pendant inflorescences may facilitate longer inflorescences. We thank C. Rogers for the image used in the graphical abstract and S. Salzman for the hummingbird outline. We thank C. Black, W.J. Kress, M. Bordelon, K. Shigematsu, R. Baker, and I. Lopez for generously providing material for this study. We are eternally grateful to all the undergraduates in the Specht Lab involved in the Heliconia project over the past 10 years $(\mathrm{H}$. Cooper, Y. Basteo-Forte, D. Wang, S. Fraley, I. Liao, J. Xiao Xue, C. Henriquez, S. Gupta, M. Ng) and funding from the Sponsored Projects for Undergraduate Research (SPUR) and Undergraduate Research Apprenticeship Program (URAP) for enabling their full participation. Thanks to L. Smith at the Evolutionary Genetics Lab at UC Berkeley for advice and lab materials used in the in-solution sequence capture. Sequencing was carried out by the DNA Technologies and Expression Analysis Cores at the UC Davis Genome Center, supported by $\mathrm{NIH}$ Shared Instrumentation Grant 1S100D010786-01. This research was supported by NSF DEB 0816661 and NSF DEB Supplement to 0816661.

\section{Appendix A}

The nomenclature used herein for Heliconia generally follows the checklist of Govaerts and Kress (2016) with a few exceptions listed below.

\begin{tabular}{ll}
\hline Our phylogeny & Govaerts and Kress (2016) \\
\hline H. aristeguietae & H. scarlatina \\
H. aurea & H. bihai \\
H. gilbertiana & H. scarlatina \\
H. laneana & H. angusta \\
H. lennartiana & H. wagneriana \\
H. lindsayana & H. sarapiquensis \\
H. longa & H. curtispatha \\
H. mincana & H. meridensis \\
H. sylvestris & H. psittacorum \\
H. tarumaensis & H. acuminata \\
H. undulata & H. irrasa \\
H. vaginalis ssp. mathiasiae & H. mathiasiae \\
H. velloziana & H. farinosa \\
\hline
\end{tabular}

\section{Appendix B}

Heliconia and outgroup voucher and GenBank accession information are in the following order: species, collection and source, ITS, ETS, trnL(UAA)-F, trnL(UAG)-rpl32, CaM, G3A, PRK. Herbarium acronyms follow (Thiers, 2012), other acronyms and abbreviations are for the following living collections: Lyon, Harold L. Lyon Arboretum at University of Hawai'i at Mānoa; US-GH, National Museum of Natural History Greenhouse, Smithsonian Institute; HeliGard, Heliconia Garden, Costa Rica (private collection of C. Black); UCBG, University of California, Berkeley, Botanical Garden; Huntington, Huntington Botanical Garden. Additional symbols are as follows: dash (-) indicates that the gene was not sequenced; asterisk $(*)$ indicates the sample was sequenced using the insolution sequence capture method (see Text); dagger $(\dagger)$ indicates a type specimen; double dagger $(\$)$ indicates affinis determination.

Heliconia abaloi G. Morales, W.J. Kress 90-3125 (US, US-GH 1990014), KY214954, -, -, KY214625, KY215330, KY215512, KY214782. H. acuminata A. Rich., J.-J. Granville s.n. (W.J. Kress 94-3689 [US, US-GH 1994742]), KY214955, KY215135, -, KY214626, KY215331, KY215513, KY214783. H. adflexa (Griggs) Standl. *, J. Wen 8741 (US), KY214956, KY215136, KY214495, KY214627, KY215332, KY215514, KY214784. H. aemygdiana Burle-Marx subsp. aemygdiana, W.J. Kress et al. 89-2863 (US), -, -, KY214496, KY214628, KY215333, KY215515, KY214785. H. aemygdiana subsp. aemygdiana, W.J. Kress et al. 96-5706 (US, USGH 1996303), KY214957, KY215137, -, KY214629, KY215334, KY215516, KY214786. H. aemygdiana subsp. transandina L. Andersson, W.J. Kress et al. 89-2939 (US), KY214958, KY215138, KY214497, KY214630, KY215335, KY215517, KY214787. H. albicosta (G.S. Daniels \& F.G. Stiles) L. Andersson *, W.J. Kress 108741A (US, INB), KY214962, KY215143, KY214499, KY214633, KY215339, KY215519, KY214790. H. angusta Vell., W.J. Kress 943688 (US), KY214963, KY215144, -, KY214634, KY215340, KY215520, KY214791. H. apparicioi Barreiros *, E.P. Killip \& A.C. Smith 26822 (US), KY214964, KY215145, KY214500, KY214635, -, -, KY214792. H. aristeguietae Abalo \& G. Morales, ex hort. (Lyon L93.132), KY215095, -, -, -, -, -, KY214895. H. arrecta W.J. Kress \& Betancur $\dagger$, W.J. Kress et al. 90-3157 (US), KY214965, KY215146, KY214501, KY214636, KY215341, KY215521, KY214793. H. atratensis Abalo \& G. Morales, W.J. Kress et al. 903142 (US), KY214966, KY215147, KY214502, KY214637, 
KY215342, KY215522, -. H. atropurpurea G.S. Daniels \& F.G. Stiles *, W.J. Kress 10-8745 (US, INB), KY214967, KY215148, KY214503, KY214638, KY215343, KY215523, KY214794. H. aurantiaca Ghiesbr. ex Lem., ex hort., W.J. Kress 94-3711 (US-GH-1994740), KY214968, KY215149, -, KY214639, KY215344, KY215524, KY214795. H. aurea G. Rodr., W.J. Kress et al. 92-3560 (US, US-GH 1992028), KY214969, KY215150, KY214504, KY214640, KY215345, KY215525, KY214796. H. badilloi Abalo \& G. Morales, W.J. Kress 89-2927 (US), KY214970, KY215151, KY214505, KY214641, KY215346, KY215526, KY214797. H. beckneri R.R. Sm., W.J. Kress et al. 92-3475 (US), -, KY215152, KY214506, KY214642, KY215347, KY215527, KY214798. H. bella W.J. Kress, C. Black s.n. (HeliGard), KY214971, -, -, KY214643, KY215348, KY215528, -. H. berryi Abalo \& G. Morales *, D.C. Wasshousen 2106 (US), KY214972, KY215153, KY214507, KY214644, KY215349, KY215529, KY214799. H. bihai (L.) L., W.J. Kress 913202 (US), KY214974, KY215155, -, KY214646, KY215350, KY215530, KY214800. H. bihai, W.J. Kress 01-6845 (US), KY214973, KY215154, -, KY214645, -, -, -. H. bourgaeana Petersen, Lyon L75. 0163, KY214975, KY215156, -, -, KY215351, KY215531, KY214801. H. brachyantha L. Andersson, W.J. Kress et al. 91-3393 (US, US-GH 1991051), -, KY215157, -, KY214647, KY215352, KY215532, KY214802. H. brachyantha , W.J. Kress 94-3648 (US, US-GH 1994733), KY214959, KY215139, KY214498, KY214631, KY215336, -, -. H. brenneri Abalo \& G. Morales, W.J. Kress et al. 89-2857 (US), KY214976, KY215158, KY214508, KY214648, KY215353, KY215533, KY214803. H. burleana Abalo \& G. Morales, W.J. Kress 91-3374 (US), KY214977, KY215159, KY214509, KY214649, KY215354, KY215534, KY214804. H. calatheaphylla G. S. Daniels \& F.G. Stiles, W.J. Kress 94-3656 (US, US-GH 1994706), KY214978, -, -, -, -, -, -. H. caquetensis Abalo \& G. Morales, W.J. Kress 90-3113 (US), KY214979, KY215160, KY214510, KY214650, KY215355, KY215535, KY214805. H. caribaea Lam., W.J. Kress 016837 (US), -, KY215161, -, -, KY215356, KY215536, -. H. caribaea, T. Prinzie \& R.F. Baker 102 (Lyon L80.0034, W.J. Kress 92-3531), KY214980, KY215162, -, KY214651, KY215357, KY215537, KY214806. H. chartacea Lane ex Barreiros, W.J. Kress 96-5689 (US, US-GH 1996299), KY214981, KY215163, -, KY214652, KY215358, KY215538, -. H. clinophila R.R. Sm., W.J. Kress 862016 (US, US-GH 1994708), -, KY215164, -, KY214653, KY215359, KY215539, -. H. colgantea R.R. Sm. ex G.S. Daniels \& F. G. Stiles *, Lyon L75.0314, KY214982, KY215165, KY214511, KY214654, KY215360, KY215540, KY214807. H. collinsiana Griggs, M. Grantham \& J. Parsons 0124-90 (UCBG 90.1610), KY214983, KY215166, -, -, -, -, -. H. collinsiana var. velutina W.J. Kress, ex hort. (Lyon L91.0113), KY214984, KY215167, KY214512, KY214655, KY215361, -, KY214808. H. combinata Abalo \& G. Morales *, J. Betancur 5953 (US), KY214985, KY215168, KY214513, KY214656, KY215362, KY215541, KY214809. H. cordata L. Andersson *, J. Betancur 5956 (US), KY214986, KY215169, KY214514, KY214657, KY215363, KY215542, KY214810. H. crassa Griggs *, E. Contreras 4341 (US), KY214987, KY215170, KY214515, KY214658, KY215364, KY215543, KY214811. H. curtispatha Petersen sensu Kress, W.J. Kress 89-2812 (US), KY214988, KY215171, KY214516, KY214659, KY215365, KY215544, KY214812. H. curtispatha sensu Andersson, W.J. Kress et al. 90-3078 (US), -, KY215172, -, KY214660, KY215366, -, KY214813. H. danielsiana W.J. Kress, W.J. Kress 10-8734A (US), KY214989, KY215173, -, -, KY215367, KY215545, -. H. darienensis L. Andersson *, B. Hammel 14873 (MO, W.J. Kress 89-2705 [US]), KY214990, KY215174, KY214517, KY214661, KY215368, KY215546, KY214814. $H$. dasyantha K. Koch \& C.D. Bouché, W.J. Kress s.n. (US-GH 1998073), -, KY215175, -, KY214662, KY215369, KY215547, -. H. densiflora Verl., P. Acevedo-Rodriguez 9867 (US-GH 1997151), -, -, -, KY214663, KY215372, KY215550, KY214815. H. dielsiana Loes., W.J. Kress et al. 89-2895 (US), KY214993, KY215176,
KY214518, KY214664, KY215373, -, KY214816. H. donstonea W.J. Kress \& Betancur, W.J. Kress et al. 89-2931 (US), KY214994, KY215177, KY214519, KY214665, KY215374, KY215551, KY214817. H. episcopalis Vell., W.J. Kress et al. 91-3309 (US), KY214995, KY215178, KY214520, KY214666, KY215375, KY215552, KY214818. H. estherae Abalo \& G. Morales, B. Echeverry et al. 92-3562A (US-GH 1992031, W.J. Kress 92-3562), -, KY215179, KY214521, KY214667, KY215376, -, KY214819. H. estiletioides Abalo \& G. Morales*, W.J. Kress et al. 93-3588 (US), KY214996, KY215180, KY214522, KY214668, KY215377, KY215553, KY214820. H. farinosa Raddi, W.J. Kress 92-3515 (US), KY214997, KY215181, KY214523, KY214669, KY215378, -, KY214821. H. fernandezii Abalo \& G. Morales *, W.J. Kress \& B. Echeverry 89-2559 (US), KY214998, KY215182, KY214524, KY214670, KY215379, KY215554, KY214822. H. fragilis Abalo \& G. Morales, W.J. Kress et al. 90-3080 (US), KY214999, KY215183, KY214525, KY214671, KY215380, KY215555, KY214823. H. fredberryana W.J. Kress †, W.J. Kress et al. 89-2947 (US), KY215000, KY215184, KY214526, KY214672, KY215381, KY215556, KY214824. H. gaiboriana Abalo \& G. Morales, W.J. Kress 89-2941 (US), KY215001, -, KY214527, KY214673, KY215382, KY215557, -. H. gigantea W.J. Kress \& Betancur $* \dagger$, W.J. Kress \& B. Echeverry 89-2621 (US), KY215002, KY215185, KY214528, KY214674, KY215383, KY215558, KY214825. H. gilbertiana Abalo \& G. Morales *, J. Betancur \& H. Mendoza 7605 (US), KY215003, KY215186, KY214529, KY214675, KY215384, KY215559, KY214826. H. gloriosa Abalo \& G. Morales, M. Collins 96.203 (Lyon L98.0166), KY215004, KY215187, KY214530, KY214676, KY215385, KY215560, KY214827. H. gracilis G.S. Daniels \& F.G. Stiles, W.J. Kress \& B. Hammel 97-5795 (US, US-GH 1997107), KY215006, KY215189, KY214531, KY214677, KY215387, KY215561, KY214828. H. griggsiana L.B. Sm., W.J. Kress et al. 89-2938 (US), KY215007, KY215190, -, -, KY215388, KY215562, KY214829. H. harlingii L. Andersson, W.J. Kress 89-2906 (US), KY215008, KY215191, KY214532, KY214678, KY215389, KY215563, KY214830. H. hirsuta L.f., W.J. Kress 11-8805 (HLDC), KY215010, -, -, -, KY215390, KY215565, -. H. hirsuta, T. Plowman 11579 (Lyon L82.0048), KY215009, KY215192, -, -, -, KY215564, -. H. holmquistiana Abalo \& G. Morales *, W.J. Kress \& B. Echeverry 89-2586 (US), KY215011, KY215193, KY214533, KY214679, KY215391, KY215566, KY214831. H. huilensis Abalo \& G. Morales, W.J. Kress et al. 903107 (US), KY215012, KY215194, KY214534, KY214680, KY215392, KY215567, KY214832. H. ignescens G.S. Daniels \& F.G. Stiles, G.S. Daniels s.n. (Lyon L80.0098), KY215013, KY215195, -, -, KY215393, -, -. H. imbricata (Kuntze) Baker, W.J. Kress 892716 (US), -, -, -, -, KY215395, -, -. H. imbricata, W.J. Kress 892831 (US), KY215014, KY215196, -, -, KY215394, KY215568, KY214833. H. impudica Abalo \& G. Morales, W.J. Kress et al. 892923 (US), KY215015, KY215197, KY214535, KY214681, KY215396, KY215569, KY214834. H. indica Lam. cv. "Spectabilis”, W.J. Kress 92-3521 (US), KY215016, KY215198, -, KY214682, KY215397, KY215570, KY214835. H. indica var. dennisiana W.J. Kress, W.J. Kress 92-3514 (US), KY215017, -, KY214536, KY214683, KY215398, KY215571, KY214836. H. indica var. micholitzii (Ridl.) W.J. Kress, W.J. Kress 92-3519 (US), KY215018, -, KY214537, KY214684, KY215399, -, KY214837. H. irrasa R.R. Sm., W.J. Kress 92-3516 (US), KY215020, KY215199, KY214538, KY214685, KY215400, KY215572, -. H. irrasa var. glabra G.S. Daniels \& F.G. Stiles *, W.J. Kress 10-8732 (US, LC), KY215021, KY215200, KY214539, KY214686, KY215401, KY215573, KY214838. H. irrasa var. irrasa *, W.J. Kress 10-8733 (US), KY215022, KY215201, KY214540, KY214687, KY215402, KY215574, KY214839. H. julianii Barreiros, W.J. Kress et al. 913269 (US, US-GH 1991046), KY215023, KY215202, -, KY214688, KY215403, KY215575, -. H. julianii, W.J. Kress et al. 91-3349 (US), -, KY215203, -, -, KY215404, -, -. H. juruana Loes., W.J. Kress 
et al. 91-3308 (US), KY215024, KY215204, KY214541, KY214689, KY215405, -, KY214840. H. kautzkiana Emygdio \& E. Santos *, W. J. Kress 89-2669 (US), KY215025, KY215205, -, KY214690, KY215406, KY215576, KY214841. H. lanata (P.S. Green) W.J. Kress, W.J. Kress 92-3508 (US), KY215026, KY215206, KY214542, KY214691, KY215407, KY215577, KY214842. H. laneana Barreiros †. W.J. Kress et al. 90-2956 (US, US-GH 1990022), KY214960, KY215140, -, KY214632, KY215337, -, KY214788. H. laneana, ex hort. (Lyon L82.921), KY215027, KY215207, KY214543, KY214692, KY215408, KY215578, -. H. lankesteri Standl. var. lankesteri, W.J. Kress et al. 92-3469 (US), KY215028, KY215208, -, KY214693, KY215409, KY215579, KY214843. H. lankesteri var. rubra G.S. Daniels \& F.G. Stiles, W.J. Kress 92-3507 (US), KY215029, -, -, KY214694, KY215410, -, KY214844. H. lasiorachis L. Andersson, ex hort. (Lyon L85.0159), KY215030, KY215209, KY214544, KY214695, -, KY215580, KY214845. H. latispatha Benth., W.J. Kress 89-2717 (US), KY215031, KY215210, KY214545, KY214696, KY215411, KY215581, -. H. latispatha, W.J. Kress et al. 90-3077 (US), KY215032, KY215211, -, -, -, -, KY214846. H. latispatha, W.J. Kress 94-3658 (US, US-GH 1994720), KY215033, -, -, -, -, -, -. H. laufao W.J. Kress, W.J. Kress 92-3528 (US), KY215034, KY215212, KY214546, KY214697, KY215412, KY215582, KY214847. H. laufao, W.J. Kress 95-5577 (US, US-GH 1995239), KY215035, -, -, -, -, -, -. H. lennartiana W. J. Kress *, R. Yamakawa 0050 (Lyon L94.0113), KY215036, KY215213, KY214547, KY214698, KY215413, KY215583, KY214848. H. lentiginosa Abalo \& G. ***Morales *, W.J. Kress et al. 86-2030 (US), KY215037, KY215214, KY214548, KY214699, KY215414, KY215584, KY214849. H. librata Griggs, W.J. Kress 923513 (US), KY215038, KY215215, -, -, KY215415, -, KY214850. $H$. lindsayana W.J. Kress $\dagger$, W.J. Kress 76-0650 (US, US-GH 19760650), -, KY215216, KY214549, KY214700, KY215416, -, KY214851. H. lindsayana \$, C.D. Specht 08-07 (NYBG), -, KY215141, -, -, KY215338, KY215518, KY214789. H. lingulata Ruiz \& Pav., Lyon L82.048, KY215039, KY215217, -, -, KY215417, -, KY214852. H. longa (Griggs) H.J.P. Winkl., W.J. Kress et al. 913381 (US), KY215040, KY215218, KY214550, KY214701, KY215418, KY215585, KY214853. H. longiflora subsp. ecuadoriensis L. Andersson, Lyon L86.0480 (W.J. Kress 94-5291 [US]), KY215041, KY215219, KY214551, KY214702, KY215419, -, KY214854. $H$. lophocarpa G.S. Daniels \& F.G. Stiles*, W.J. Kress 10-8746 (US, INB), KY215042, KY215220, KY214552, KY214703, KY215420, KY215586, KY214855. H. lourteigiae Emygdio \& E. Santos*, J.-J. Granville 11348 (Lyon L91.0309, W.J. Kress 94-5250 [US]), KY215043, KY215221, KY214553, KY214704, KY215421, KY215587, KY214856. H. lozanoi Abalo \& G. Morales, W.J. Kress et al. 91-3373 (US), KY215044, KY215222, KY214554, KY214705, KY215422, KY215588, KY214857. H. lutea W.J. Kress*, G. McPherson 14041 (US), KY215045, KY215223, KY214555, KY214706, KY215423, KY215589, KY214858. H. lutheri W.J. Kress* †,W.J. Kress et al. 89-2925 (US), KY215046, KY215224, KY214556, KY214707, KY215424, KY215590, KY214859. H. maculata W.J. Kress, W.J. Kress 82-1406 (US, Lyon L88.0430), KY215047, KY215225, -, KY214708, KY215425, -, -. H. magnifica W.J. Kress, D. Carli 142B, ex hort. (Lyon L90.0146), KY215048, KY215226, KY214557, KY214709, KY215426, KY215591, KY214860. H. marginata (Griggs) Pittier, W.J. Kress 91-3314 (US), KY215049, KY215227, KY214558, KY214710, KY215427, KY215592, KY214861. H. mariae Hook.f., W.J. Kress 89-2843 (US), KY215050, KY215228, -, KY214711, KY215428, KY215593, KY214862. H. meridensis Klotzsch, W.J. Kress 91-3210 (US), KY215052, KY215230, KY214559, KY214713, KY215430, KY215594, KY214864. H. metallica Planch. \& Linden ex Hook., W.J. Kress 11-8802 (PMA), KY215053, -, -, -, KY215431, KY215595, -. H. metallica, W.J. Kress 11-8803 (HLDC), KY215054, -, -, -, KY215432, KY215596, -. H. mincana Abalo \& G. Morales *, W.J. Kress et al. 92-3554 (US), KY215055,
KY215231, KY214560, KY214714, KY215433, KY215597, KY214865. H. mooreana R.R. Sm. *, J.G. Ortega 49 (MO), KY215056, KY215232, KY214561, KY214715, KY215434, KY215598, KY214866. H. mucilagina Abalo \& G. Morales *, W.J. Kress \& B. Echeverry 89-2578 (US), KY215057, KY215233, KY214562, KY214716, KY215435, KY215599, KY214867. H. mutisiana Cuatrec., W.J. Kress 90-3110 (US), KY215058, KY215234, -, KY214717, KY215436, KY215600, KY214868. H. narinensis Abalo \& G. Morales, W.J. Kress et al. 90-3095 (US), KY215059, KY215235, KY214563, KY214718, KY215437, KY215601, KY214869. H. necrobracteata W.J. Kress, ex hort. (Lyon L72.0014), KY215060, KY215236, KY214564, KY214719, KY215438, -, KY214870. H. nigripraefixa Dodson \& A.H. Gentry, W.J. Kress et al. 89-2907 (US, Lyon L90.0110), KY215061, KY215237, KY214565, KY214720, KY215439, KY215602, KY214871. H. nutans Woodson *, W.J. Kress 94-4906 (US, US-GH 1994621), KY215062, KY215238, KY214566, KY214721, KY215440, KY215603, KY214872. H. obscura Dodson, W.J. Kress et al. 89-2908 (US), KY215063, KY215239, KY214567, KY214722, KY215441, KY215604, KY214873. H. obscura subsp. dichroma W.J. Kress $\dagger$, W. J. Kress et al. 89-2866 (US, Lyon L90.0115), KY215064, KY215240, KY214568, KY214723, KY215442, KY215605, -. H. obscuroides L. Andersson, W.J. Kress et al. 90-3065 (US), KY215065, KY215241, KY214569, KY214724, KY215443, KY215606, -. H. oleosa Abalo \& G. Morales, W.J. Kress et al. 91-3379 (US, US-GH 1991049), KY215066, KY215242, KY214570, KY214725, KY215444, KY215607, KY214874. H. orthotricha L. Andersson, W.J. Kress 965696 (US), -, KY215243, -, -, -, -, -. H. osaensis Cufod., W.J. Kress \& C.S. Roesel 89-2728 (US), KY215067, KY215244, KY214571, KY214726, KY215445, KY215608, -. H. paka A.C. Sm., US-GH 1996352, KY215068, KY215245, -, KY214727, KY215446, KY215609, KY214875. H. paludigena Abalo \& G. Morales*, T.W. Flynn et al. 4110 (US), KY215069, KY215246, KY214572, KY214728, KY215447, KY215610, KY214876. H. papuana W.J. Kress, W.J. Kress 92-3509 (US), KY215070, -, KY214573, KY214729, KY215448, KY215611, -. H. pardoi Abalo \& G. Morales, W.J. Kress et al. 89-2922 (US, Lyon L90.0111), KY215071, KY215247, KY214574, KY214730, -, -, -. H. pastazae L. Andersson, W.J. Kress et al. 89-2896 (US), KY215081, KY215258, KY214578, KY214738, KY215457, -, KY214882. H. pastazae, W.J. Kress et al. 90-3116 (US), -, KY215249, -, KY214732, -, KY215613, -. H. pastazae, W.J. Kress et al. 96-5731 (US), KY215072, KY215248, KY214575, KY214731, KY215449, KY215612, KY214877. H. pendula Wawra, W.J. Kress 94-3663 (US, US-GH 1994650), KY215073, KY215250, -, KY214733, KY215450, KY215614, -. H. penduloides Loes., US-GH 1997152, KY215074, KY215251, -, -, -, -, -. H. peteriana Abalo \& G. Morales *, W.J. Kress 89-2886 (US), KY215075, KY215252, KY214576, KY214734, KY215451, KY215615, KY214878. H. platystachys Baker, W.J. Kress 11-8794 (PMA), KY215076, KY215253, -, KY214735, KY215452, KY215616, -. H. pogonantha Cufod., W.J. Kress \& C.S. Roesel 892834 (US), KY215078, KY215255, KY214577, KY214737, KY215454, KY215618, KY214880. H. pogonantha var. holerythra G. S. Daniels \& F.G. Stiles, W.J. Kress 10-8749 (US, INB), KY215079, KY215256, -, -, KY215455, KY215619, -. H. pseudoaemygdiana Emygdio \& E. Santos, F. Berry 593 K (US-GH 1994652, W.J. Kress 94-5383), KY215080, KY215257, -, -, KY215456, KY215620, KY214881. H. psittacorum L.f., W.J. Kress 94-5361 (US, US-GH 1994628), KY215082, KY215259, -, -, KY215458, KY215621, KY214883. H. ramonensis G.S. Daniels \& F.G. Stiles $\ddagger$, C.D. Specht 08-08 (NYBG), KY214961, KY215142, -, -, -, -, -. H. regalis L. Andersson, W.J. Kress et al. 89-2928 (US), KY215083, KY215260, -, KY214739, KY215459, -, KY214884. H. reptans Abalo \& G. Morales, W.J. Kress et al. 91-3380 (US, US-GH 1991044), KY215084, -, -, -, KY215460, -, KY214885. H. reticulata (Griggs) H.J.P. Winkl., W.J. Kress 89-2756 (US), KY215085, KY215261, KY214579, 
KY214740, KY215461, -, KY214886. H. rhodantha Abalo \& G. Morales, W.J. Kress 90-3164 (US), -, KY215262, KY214580, KY214741, KY215462, KY215622, KY214887. H. richardiana Miq., J.-J. Granville 11340 (US-GH 1991052, W.J. Kress 94-3672), KY215086, KY215263, KY214581, KY214742, KY215463, KY215623, -. H. rigida Abalo \& G. Morales, W.J. Kress et al. 91-3384 (US), KY215087, KY215264, KY214582, KY214743, KY215464, KY215624, KY214888. H. riopalenquensis Dodson \& A.H. Gentry, W.J. Kress et al. 89-2904 (US), KY215088, KY215265, -, -, KY215465, KY215625, KY214889. H. robertoi Abalo \& G. Morales *, W.J. Kress \& B. Echeverry 89-2613 (US), KY215089, KY215266, KY214583, KY214744, KY215466, KY215626, KY214890. H. robusta Pax *, B. Echeverry et al. 121 (US), KY215090, KY215267, KY214584, KY214745, KY215467, KY215627, KY214891. $H$. rodriguensis Aristeg., W.J. Kress et al. 91-3197 (US), -, KY215268, KY214585, KY214746, KY215468, KY215628, KY214892. H. rodriguezii F.G. Stiles, W.J. Kress \& B.E. Hammel 97-5794 (US, US-GH 1997106), KY215091, KY215269, -, KY214747, -, -, -. H. rostrata Ruiz \& Pav., W.J. Kress et al. 89-2860 (US), KY215092, KY215270, -, KY214748, KY215469, KY215629, KY214893. H. sanctae-martae L. Andersson*, B. Echeverry et al. 92-3553 (US), KY215093, KY215271, KY214586, KY214749, KY215470, KY215630, KY214894. H. sarapiquensis G.S. Daniels \& F.G. Stiles, W.J. Kress 89-2816 (US), KY215094, KY215272, -, KY214750, KY215471, KY215631, -. H. schiedeana Klotzsch, W.J. Kress 94-3659 (US, USGH 1994661), KY215096, KY215273, -, KY214751, KY215472, KY215632, KY214896. H. schumanniana Loes., T. Plowman 11343 (Lyon L82.0648), KY215097, KY215274, -, KY214752, -, -, KY214897. H. sclerotricha Abalo \& G. Morales, W.J. Kress et al. 892915 (US), KY215098, KY215275, KY214587, KY214753, KY215473, KY215633, KY214898. H. secunda R.R. Sm.*, W.J. Kress s.n. (US), KY215099, KY215276, KY214588, KY214754, KY215474, KY215634, KY214899. H. signa-hispanica Abalo \& G. Morales*, J. Betancur 5960 (US), KY215100, KY215277, KY214589, KY214755, KY215475, KY215635, KY214900. H. solomonensis W.J. Kress, W.J. Kress 92-3526 (US), KY215101, KY215278, KY214590, KY214756, KY215476, KY215636, -. H. spathocircinata Aristeg.*, W. Johnson 300 (US), KY215106, KY215282, KY214593, KY214759, KY215481, KY215641, KY214903. H. spiralis Abalo \& G. Morales*, W.J. Kress 89-2631 (US), KY215107, KY215283, KY214594, KY214760, KY215482, KY215642, KY214904. H. spissa Griggs, D. Orr 91-19 (Lyon L97.0315), KY215108, KY215284, -, -, -, KY215643, -. H. standleyi J.F. Macbr. *, ex hort. (Lyon L80.0094), KY215109, KY215285, KY214595, KY214761, KY215483, KY215644, KY214905. H. stella-maris Abalo \& G. Morales*, W.J. Kress et al. 90-3127 (US), KY215110, KY215286, KY214596, KY214762, KY215484, KY215645, KY214906. H. stilesii W.J. Kress, W.J. Kress \& C.S. Roesel 89-2721 (US), KY215111, KY215287, KY214597, KY214763, KY215485, KY215646, KY214907. H. stricta Huber, W.J. Kress 78-1043 (US, US-GH 1994637), KY215112, KY215288, -, -, KY215486, KY215647, KY214908. H. subulata Ruiz \& Pav., Lyon L88.0694, KY215113, KY215289, -, -, KY215487, KY215648, -. H. sylvestris (Gleason) L.B. Smith, W.J. Kress 943612 (US, US-GH 1994641), KY215114, KY215290, KY214598, KY214764, KY215488, KY215649, -. H. talamancana G.S. Daniels \& F.G. Stiles*, G.S. Daniels s.n. (Lyon L80.0060), KY215115, KY215291, KY214599, KY214765, KY215489, KY215650, KY214909. H. tarumaensis Barr., W.J. Kress et al. 91-3226 (US, USGH 1991047), -, KY215292, -, -, -, KY215651, -. H. tarumaensis, W.J. Kress 97-5755 (US, US-GH 1997013), KY215116, KY215293, -, KY214766, KY215490, KY215652, KY214910. H. terciopela W.J. Kress \& Betancur, W.J. Kress et al. 90-3133 (US), KY215117, -, KY214600, KY214767, KY215491, KY215653, KY214911. H. thomasiana W.J. Kress, W.J. Kress 92-3529 (US), KY215118, -, -, KY214768, KY215492, KY215654, KY214912. H. timothei L. Andersson *, T. Plowman et al. 6744 (US), KY215119, KY215294, -,
KY214769, KY215493, -, -. H. titanum W.J. Kress \& Betancur †, W. J. Kress et al. 90-3168 (US), KY215120, KY215295, -, KY214770, KY215494, KY215655, KY214913. H. tortuosa Griggs, D. Campbell s.n. (UCBG 89.1273), -, KY215296, -, -, KY215495, -, -. H. tortuosa, W.J. Kress et al. 92-3477 (US, US-GH 1992034), KY215121, KY215297, KY214601, KY214771, KY215496, KY215656, KY214914. H. umbrophila G.S. Daniels \& F.G. Stiles, W.J. Kress 892835 (US), KY215122, KY215298, -, KY214772, KY215497, KY215657, KY214915. H. undulata (G.S. Daniels \& F.G. Stiles) L. Andersson, W.J. Kress 76-519 (Duke 84-043), KY215019, -, -, -, -, -, -. H. vaginalis Benth., W.J. Kress \& C.S. Roesel 89-2821 (US, USGH 1994644), KY215105, KY215281, KY214592, KY214758, KY215480, KY215640, KY214902. H. vaginalis, W.J. Kress 94-3741 (US, US-GH 1994645), KY215123, KY215299, -, -, KY215498, KY215658, -. H. vaginalis subsp. mathiasiae (G.S. Daniels \& F.G. Stiles) L. Andersson, W.J. Kress 79-1105 (US, US-GH 1994617), KY215051, KY215229, -, KY214712, KY215429, -, KY214863. H. vaginalis subsp. mathiasiae, W.J. Kress 94-3661 (US), KY215005, KY215188, -, -, KY215386, -, -. H. vaginalis subsp. mathiasiae, W. J. Kress 10-8736A (US), KY215131, KY215309, -, -, KY215508, KY215665, -. H. vaginalis subsp. vaginalis, W.J. Kress 11-8800 (PMA), KY214991, -, -, -, KY215370, KY215548, -. H. vaginalis subsp. vaginalis, W.J. Kress 11-8808 (HLDC), KY214992, -, -, -, KY215371, KY215549, -. H. vellerigera Poepp., W.J. Kress et al. 965678 (US, US-GH 1996294), -, KY215300, -, -, KY215499, -, -. H. velloziana Emygdio *, L. Emygdio \& W.J. Kress 90-2967 (US, US-GH 1994646), KY215124, KY215301, KY214602, KY214773, KY215500, KY215659, KY214916. H. velutina L. Andersson, W.J. Kress et al. 89-2874 (US), -, KY215302, KY214603, KY214774, KY215501, KY215660, KY214917. H. venusta Abalo \& G. Morales *, R. Montgomery 87962 (US), KY215125, KY215303, KY214604, KY214775, KY215502, KY215661, KY214918. H. villosa Klotzsch, W.J. Kress et al. 91-3207 (US), KY215126, KY215304, -, KY214776, KY215503, -, KY214919. H. virginalis Abalo \& G. Morales, W.J. Kress et al. 89-2917 (US), KY215127, KY215305, KY214605, KY214777, KY215504, KY215662, KY214920. H. wagneriana Petersen, W.J. Kress 89-2846 (US), KY215128, KY215306, KY214606, KY214778, KY215505, KY215663, KY214921. H. willisiana Abalo \& G. Morales, M. Collins EC9957 (US-GH 1999205), KY215130, KY215308, -, -, KY215507, -, -. H. ×rauliniana Barreiros, J. Abalo s.n. * A, ex hort. (Lyon L94.0107), KY215132, KY215310, -, KY214780, KY215509, -, KY214923. H. ×rauliniana, J. Abalo s.n. * B, ex hort. (Lyon L94.0107), -, KY215311, -, -, KY215510, -, KY214924. H. xanthovillosa W.J. Kress, R. Montgomery s.n., ex hort. (Lyon L94.0034), KY215133, KY215312, -, -, -, KY215666, -. H. zebrina Plowman, W.J. Kress \& H. Kenn. *, ex hort. (Lyon L85.0195), KY215134, KY215313, KY214608, KY214781, KY215511, KY215667, KY214925. H. sp., ex hort. (US-GH 1993089, W.J. Kress 94-3677), KY215077, KY215254, -, KY214736, KY215453, KY215617, KY214879. H. sp., Kress 94-3698, -, KY215280, KY214591, KY214757, KY215479, KY215639, -. H. sp. *, W.J. Kress et al. 96-5694 (US, US-GH 1996193), KY215129, KY215307, KY214607, KY214779, KY215506, KY215664, KY214922. H. sp., C. D. Specht 06-08 (NYBG), KY215102, -, -, -, KY215477, KY215637, KY214901. H. sp., C.D. Specht 08-05 (NYBG), KY215103, KY215279, -, -, KY215478, KY215638, -. Canna jaegeriana Urb., Sass et al. (2016), KY214934, KY214942, KY214481, KY214611, KY215316, -, -. Ensete superbum (Roxb.) Cheesman, Sass et al. (2016), KY214928, KY214943, KY214484, KY214614, KY215319, -, -. Ensete ventricosum (Welw.) Cheesman *, M. Bartlett 0908 (Specht lab, UCB), KY214929, KY214944, KY214485, KY214615, KY215320, -, -. Globba winitii C.H. Wright, Sass et al. (2016), KY214935, -, KY214483, KY214613, KY215318, -, -. Halopegia azurea (K. Schum.) K. Schum., Sass et al. (2016), KY214936, -, KY214479, KY214609, KY215314, -, -. Monocostus uniflorus (Poepp. ex Petersen) Maas *, US-GH 1994725, KY214937, -, 
KY214482, KY214612, KY215317, -, -. Musa sp., Sass et al. (2016), KY214926, KY214948, KY214489, KY214619, KY215324, -, - . Musa basjoo Siebold \& Zucc. *, D. Barry 1970 (UCBG 89.0873), KY214930, KY214945, KY214486, KY214616, KY215321, -, -. Musa coccinea Andrews, Sass et al. (2016), KY214932, KY214946, KY214487, KY214617, KY215322, -, -. Musa ornata Roxb., Sass et al. (2016), KY214931, KY214947, KY214488, KY214618, KY215323, -, -. Musella lasiocarpa (Franch.) C.Y. Wu ex H.W. Li $*$, Huntington 86298, KY214927, KY214949, KY214490, KY214620, KY215325, -. Orchidantha maxillarioides (Ridl.) K. Schum., Sass et al. (2016), KY214938, KY214950, KY214491, KY214621, KY215326, -. Ravenala madagascariensis Sonn. *, M. Bartlett 08017 (Specht lab, UCB), KY214941, KY214951, KY214492, KY214622, KY215327, -. Strelitzia caudata R.A. Dyer, Sass et al. (2016), KY214940, KY214952, KY214493, KY214623, KY215328, -. Strelitzia reginae Banks $*$, M. Bartlett 06-07 (ex hort., Spruce St, Berkeley CA, USA), KY214939, KY214953, KY214494, KY214624, KY215329, -. Thaumatococcus daniellii (Benn.) Benth., Sass et al. (2016), KY214933, -, KY214480, KY214610, KY215315, -.

\section{Appendix C. Supplementary material}

Supplementary data associated with this article can be found, in the online version, at http://dx.doi.org/10.1016/j.ympev.2016.12. 001.

\section{References}

Abalo, J.E., 1983. Doce (12) heliconias neuvas del Ecuador. Phytologia 52, 387-413. Abrahamczyk, S., Souto-Vilarós, D., Renner, S.S., 2014. Escape from extreme specialization: passionflowers, bats and the sword-billed hummingbird. Proc. R. Soc. B Biol. Sci. 281, 20140888.

Andersson, L., 1998. Musaceae. In: Kubitzki, K. (Ed.), The Families and Genera of Vascular Plants. IV. Flowering Plants - Monocotyledons - Alismatanae and Commelinanae (Except Gramineae). Springer, Berlin, pp. 296-301.

Andersson, L., 1992. Revision of Heliconia subgen. Taeniostrobus and subgen. Heliconia (Musaceae-Heliconioideae). Opera Bot. 11, 5-98.

Andersson, L., 1985a. Revision of Heliconia subgen. Stenochlamys (MusaceaeHeliconioideae). Opera Bot. 82, 5-123.

Andersson, L., 1985b. Musaceae, in: Harling, G., Sparre, B. (Eds.), Flora of Ecuador 22. pp. $1-86$

Andersson, L., 1981. Revision of Heliconia sect. Heliconia (Musaceae). Nord. J. Bot. 1 $759-784$

Baldwin, B.G., Markos, S., 1998. Phylogenetic utility of the external transcribed spacer (ETS) of 18S-26S rDNA: congruence of ETS and ITS trees of Calycadenic (Compositae). Mol. Phylogenet. Evol. 10, 449-463.

Barker, D., Pagel, M., 2005. Predicting functional gene links from phylogeneticstatistical analyses of whole genomes. PLoS Comput. Biol. 1, e3. http://dx.doi. org/10.1371/journal.pcbi.0010003.

Barrett, C.F., Specht, C.D., Leebens-Mack, J., Stevenson, D.W., Zomlefer, W.B., Davis, J I., 2014. Resolving ancient radiations: can complete plastid gene sets elucidate deep relationships among the tropical gingers (Zingiberales)? Ann. Bot. 113, 119-133. http://dx.doi.org/10.1093/aob/mct264.

Beaulieu, J.M., Donoghue, M.J., 2013. Fruit evolution and diversification in campanulid angiosperms. Evolution 67, 3132-3144. http://dx.doi.org/10.1111/ evo.12180.

Berry, F., Kress, W.J., 1991. Heliconia: An Identification Guide. Smithsonian Institution Press, Washington, DC.

Cheney, E.S., Hayman, N.W., 2009. The Chiwaukum Structural Low: Cenozoic shortening of the central Cascade Range, Washington State, USA. Bull. Geol. Soc. Am. 121, 1135-1153, http://dx.doi.org/10.1130/B26446.1.

Cohen, K.M., Finney, S.C., Gibbard, P.L., Fan, J.-X., 2013. The ICS internationa chronostratigraphic chart v 2016/04. Episodes 36, 199-204.

Colwell, R.K., Naskrecki, P., 1999. The evolution of host-plant affiliation, body, size and sexual dimrphism in hummingbird flower mites (Ascidae: Rhinoseius and Tropicoseius), in: Needham, G.R., Mitchell, R., Horn, D.J., Welbourn, W.C. (Eds.), Acarology 9. Symposia (Ninth International Congress of Acarology. Ohio Biological Survey, Columbus, Ohio, pp. 76-86.

Côrtes, M.C., Uriarte, M., Lemes, M.R., Gribel, R., Kress, W.J., Smouse, P.E., Bruna, E. M., 2013. Low plant density enhances gene dispersal in the Amazonian understory herb Heliconia acuminata. Mol. Ecol. 22, 5716-5729. http://dx.doi. org/10.1111/mec.12495.

Dobkin, D.S., 1990. Distribution patterns of hummingbird flower mites (Gamasida: Ascidae) in relation to floral availability on Heliconia inflorescences. Behav. Ecol. 1, 131-139.
Dobkin, D.S., 1985. Heterogeneity of tropical floral microclimates and the response of hummingbird flower mites. Ecology 66, 536-543.

Dos Reis, M., Yang, Z., 2011. Approximate likelihood calculation on a phylogeny for bayesian estimation of divergence times. Mol. Biol. Evol. 28, 2161-2172. http:// dx.doi.org/10.1093/molbev/msr045.

Doyle, J.A., Hickey, L.J., 1976. Pollen and leaves from the mid-Cretaceous Potomac Group and their bearing on early angiosperm evolution. In: Beck, C.B. (Ed.), Origin and Early Evolution of Angiosperms. Columbia University Press, New York, pp. 139-206.

Doyle, J.J., Doyle, J.L., 1987. A rapid DNA isolation procedure for small quantities of fresh leaf tissue. Phytochem. Bull. 19, 11-15.

EDGE: Evolutionarily Distinct \& Globally Endangered [WWW Document], 2016. Zool. Soc. London. URL http://www.edgeofexistence.org/.

Edwards, K., Johnstone, C., Thompson, C., 1991. A simple and rapid method for the preparation of plant genomic DNA for PCR analysis. Nucl. Acids Res. 19, 1349.

Feinsinger, P., 1978. Ecological interactions between plants and hummingbirds in a successional tropical community. Ecol. Monogr. 48, 269-287.

Felsenstein, J., 2012. A comparative method for both discrete and continuous characters using the threshold model. Am. Nat. 179, 145-156. http://dx.doi.org/ $10.1086 / 663681$

Felsenstein, J., 2005. Using the quantitative genetic threshold model for inferences between and within species. Philos. Trans. R. Soc. London B Biol. Sci. 360, 14271434. http://dx.doi.org/10.1098/rstb.2005.1669.

FitzJohn, R.G., Pennell, M.W., Zanne, A.E., Stevens, P.F., Tank, D.C., Cornwell, W.K., 2014. How much of the world is woody? J. Ecol. 102, 1266-1272. http://dx.doi. org/10.5061/dryad.63q27/2.

Galen, C., Gregory, T., 1989. Interspecific pollen transfer as a mechanism of competition: consequences of foreign pollen contamination for seed set in the alpine wildflower, Polemonium viscosum. Oecologia 81, 120-123.

Givnish, T.J., Barfuss, M.H.J., Van Ee, B., Riina, R., Schulte, K., Horres, R., Gonsiska, P.A., Jabaily, R.S., Crayn, D.M., Smith, J.A.C., Winter, K., Brown, G.K., Evans, T.M., Holst, B.K., Luther, H., Till, W., Zizka, G., Berry, P.E., Sytsma, K.J., 2014. Adaptive radiation, correlated and contingent evolution, and net species diversification in Bromeliaceae. Mol. Phylogenet. Evol. 71, 55-78. http://dx.doi.org/10.1016/j. ympev.2013.10.010.

Govaerts, R., Kress, W.J., 2016. World Checklist of Heliconiaceae [WWW Document]. Facil. by R. Bot. Gard. Kew. <http://apps.kew.org/wcsp/> (accessed 5.26.16)

Graham, S.W., Iles, W.J.D., 2009. Different gymnosperm outgroups have (mostly) congruent signal regarding the root of flowering plant phylogeny. Am. J. Bot. 96, 216-227. http://dx.doi.org/10.3732/ajb.0800320.

Graham, S.W., Olmstead, R.G., 2000. Utility of 17 chloroplast genes for inferring the phylogeny of the basal Angiosperms. Am. J. Bot. 87, 1712-1730.

Graham, S.W., Olmstead, R.G., Barrett, S.C.H., 2002. Rooting phylogenetic trees with distant outgroups: a case study from the commelinoid monocots. Mol. Biol. Evol. 19, 1769-1781.

Graham, S.W., Reeves, P.A., Burns, A.C.E., Olmstead, R.G., 2000. Microstructural changes in noncoding chloroplast DNA: interpretation, evolution, and utility of indels and inversions in basal angiosperm phylogenetic inference. Int. J. Plant Sci. 161, S83-S96.

Hanson, C.B., 1996. Stratigraphy and vertebrate faunas of the BridgerianDuchesnean Clarno Formation, north-central Oregon. In: Prothero, D.R., Emry, R.J. (Eds.), The Terrestrial Eocene-Oligocene Transition in North America. Cambridge University Press, Cambridge, pp. 206-239.

Heled, J., Drummond, A.J., 2010. Bayesian inference of species trees from multilocus data. Mol. Biol. Evol. 27, 570-580. http://dx.doi.org/10.1093/molbev/msp274.

Huelsenbeck, J.P., Andolfatto, P., Huelsenbeck, E.T., 2011. Structurama: Bayesian inference of population structure. Evol. Bioinforma. 7, 55-59. http://dx.doi.org/ 10.4137/EBO.S6761.

Huelsenbeck, J.P., Nielsen, R., Bollback, J.P., 2003. Stochastic mapping of morphological characters. Syst. Biol. 52, 131-158. http://dx.doi.org/10.1080/ 10635150390192780.

Iles, W.J.D., Smith, S.Y., Gandolfo, M.A., Graham, S.W., 2015. Monocot fossils suitable for molecular dating analyses. Bot. J. Linn. Soc. 178, 346-374.

Isaac, N.J.B., Turvey, S.T., Collen, B., Waterman, C., Baillie, J.E.M., 2007. Mammals on the EDGE: conservation priorities based on threat and phylogeny. PLoS ONE 2 , e296. http://dx.doi.org/10.1371/journal.pone.0000296.

Isaza, L., Marulanda, M.L., López, A.M., 2012. Genetic diversity and molecular characterization of several Heliconia species in Colombia. Genet. Mol. Res. 11, 4552-4563.

Jónsson, H., Ginolhac, A., Schubert, M., Johnson, P.L.F., Orlando, L., 2013. mapDamage2.0: Fast approximate Bayesian estimates of ancient DNA damage parameters. Bioinformatics 29, 1682-1684. http://dx.doi.org/10.1093/ bioinformatics/btt193.

Kay, K.M., Reeves, P.A., Olmstead, R.G., Schemske, D.W., 2005. Rapid speciation and the evolution of hummingbird pollination in Neotropical Costus subgenus Costus (Costaceae): evidence from nrDNA ITS and ETS sequences. Am. J. Bot. 92, 1899-1910.

Kembel, S.W., Cowan, P.D., Helmus, M.R., Cornwell, W.K., Morlon, H., Ackerly, D.D., Blomberg, S.P., Webb, C.O., 2010. Picante: R tools for integrating phylogenies and ecology. Bioinformatics 26, 1463-1464. http://dx.doi.org/10.1093/ bioinformatics/btq166.

Konieczny, A., Ausubel, F.M., 1993. A procedure for mapping Arabidopsis mutations using co-dominant ecotype-specific PCR-based markers. Plant J. 4, 403-410.

Kress, W.J., 1990. The taxonomy of the Old World Heliconia (Heliconiaceae). Allertonia 6, 1-58. 
Kress, W.J., 1985. Bat pollination of an Old World Heliconia. Biotropica 17, 302-308. Kress, W.J., 1984. Systematics of Central American Heliconia (Heliconiaceae) with pendant inflorescences. J. Arnold Arbor. 65.

Kress, W.J., 1983. Crossability barriers in Neotropical Heliconia. Ann. Bot. 52, $131-$ 147.

Kress, W.J., Betancur, J., Echeverry, B., 2004. Heliconias: Llamaradas de la Selva Colombiana. Cristina Uribe Editores, Bogotá.

Kress, W.J., Betancur, J., Roesel, C.S., Echeverry, B., 1993. Lista preliminar de las heliconias de Colombia y cinco especies nuevas. Caldasia 17, 183-197.

Lagomarsino, L.P., Condamine, F.L., Antonelli, A., Mulch, A., Davis, C.C., 2016. The abiotic and biotic drivers of rapid diversification in Andean bellflowers (Campanulaceae). New Phytol. 210, 1430-1442.

Lanfear, R., Calcott, B., Ho, S.Y.W., Guindon, S., 2012. PartitionFinder: combined selection of partitioning schemes and substitution models for phylogenetic analyses. Mol. Biol. Evol. 29, 1695-1701. http://dx.doi.org/10.1093/molbev/ mss020.

Maddison, W.P., 1997. Gene trees in species trees. Syst. Biol. 46, 523-536.

Maddison, W.P., FitzJohn, R.G., 2015. The unsolved challenge to phylogenetic correlation tests for categorical characters. Syst. Biol. 64, 127-136. http://dx.doi. org/10.1093/sysbio/syu070.

Maddison, W.P., Maddison, D.R., 2009. Mesquite: a modular system for evolutionary analysis.

Manchester, S.R., 1994. Fruits and seeds of the Middle Eocene Nut Beds flora, Clarno Formation. Oregon. Palaeontogr. Am. 58, 1-205.

Manchester, S.R., Kress, W.J., 1993. Fossil bananas (Musaceae): Ensete oregonense sp. nov. from the Eocene of western North America and its phytogeographic significance. Am. J. Bot. 80, 1264-1272. http://dx.doi.org/10.2307/2445709.

Marouelli, L.P., Inglis, P.W., Ferreira, M.A., Buso, G.S.C., 2010. Genetic relationships among Heliconia (Heliconiaceae) species based on RAPD markers. Genet. Mol. Res. 9, 1377-1387. http://dx.doi.org/10.4238/vol9-3gmr847.

Mayr, G., 2007. New specimens of the early Oligocene Old World hummingbird Eurotrochilus inexpectatus. J. Ornithol. 148, 105-111. http://dx.doi.org/10.1007/ s10336-006-0108-y.

Mayr, G., 2004. Old World fossil record of modern-type hummingbirds. Science 304, 861-864. http://dx.doi.org/10.1126/science.1096856.

McDade, L.A., 1983. Long-tailed hermit hummingbird visits to inflorescence color morphs of Heliconia irrasa. Condor 85, 360-364.

McGuire, J.A., Witt, C.C., Remsen, J.V., Corl, A., Rabosky, D.L., Altshuler, D.L., Dudley, R., 2014. Molecular phylogenetics and the diversification of hummingbirds. Curr. Biol. 24, 910-916. http://dx.doi.org/10.1016/j.cub.2014.03.016.

McKenna, D.D., Farrell, B.D., 2006. Tropical forests are both evolutionary cradles and museums of leaf beetle diversity. Proc. Natl. Acad. Sci. USA 103, 10947-10951.

Meyer, M., Kircher, M., 2010. Illumina sequencing library preparation for highly multiplexed target capture and sequencing. Cold Spring Harb Protoc 2010. http://dx.doi.org/10.1101/pdb.prot5448. doi:10.1101/pdb.prot5448.

Miller, M.A., Pfeiffer, W., Schwartz, T., 2010. Creating the CIPRES Science Gateway for inference of large phylogenetic trees. In: 2010 Gateway Computing Environments Workshop (GCE). IEEE, pp. 1-8. http://dx.doi.org/10.1109/ GCE.2010.5676129.

Mirarab, S., Reaz, R., Bayzid, S., Zimmermann, T., Swenson, M.S., Warnow, T., 2014. ASTRAL: Genome-scale coalescent-based species tree estimation. Bioinformatics 30, 541-548. http://dx.doi.org/10.1093/bioinformatics/btu462.

Müller, J., Müller, K., Neinhuis, C., Quandt, D., 2010. PhyDE - Phylogenetic Data Editor.

Pagel, M., 1994. Detecting correlated evolution on phylogenies: a general method for the comparative analysis of discrete characters. Proc. R. Soc. B Biol. Sci. 255, 37-45. http://dx.doi.org/10.1098/rspb.1994.0006.

Peñalba, J.V., Smith, L.L., Tonione, M.A., Sass, C., Hykin, S.M., Skipwith, P.L., McGuire, J.A., Bowie, R.C.K., Moritz, C., 2014. Sequence capture using PCR-generated probes: a cost-effective method of targeted high-throughput sequencing for non-model organisms. Mol. Ecol. Resour. 14, 1000-1010. http://dx.doi.org/ 10.1111/1755-0998.12249.

Pessoa, E., Britto, J., Finotti, A.S., Moraes, G.J., 2015. Diversity and population dynamics of Ascidae, Blattisociidae and Melicharidae (Acari: Mesostigmata) in tropical flowers in Brazil. Exp. Appl. Acarol. 66, 203-217. http://dx.doi.org/ 10.1007/s10493-015-9904-5.

Rannala, B., Yang, Z., 2007. Inferring speciation times under an episodic molecular clock. Syst. Biol. 56, 453-466. http://dx.doi.org/10.1080/10635150701420643.

Redding, D.W., Mooers, A.Ø., 2006. Incorporating evolutionary measures into conservation prioritization. Conserv. Biol. 20, 1670-1678. http://dx.doi.org/ 10.1111/j.1523-1739.2006.00555.x.

Retallack, G.J., Bestland, E.A., Fremd, T.J., 2000. Eocene and oligocene paleosols of central oregon. Geol. Soc. Am. Spec. Pap. 344, 1-192.

Revell, L.J., 2014. Ancestral character estimation under the threshold model from quantitative genetics. Evolution 68, 743-759. http://dx.doi.org/10.1111/ evo.12300.

Revell, L.J., 2012. Phytools: an R package for phylogenetic comparative biology (and other things). Methods Ecol. Evol. 3, 217-223. http://dx.doi.org/10.1111/j.2041210X.2011.00169.x.

Rieseberg, L.H., Brouillet, L., 1994. Are many plant species paraphyletic? Taxon 43, 21-32.

Roalson, E., Roberts, W.R., 2016. Distinct processes drive diversification in different clades of Gesneriaceae. Syst. Biol. 65, 662-684. http://dx.doi.org/10.1093/ sysbio/syw012.
Ronquist, F., Huelsenbeck, J.P., 2003. MrBayes3: Bayesian phylogenetic inference under mixed models. Bioinformatics 19, 1572-1574.

Ronquist, F., Teslenko, M., van der Mark, P., Ayres, D.L., Darling, A., Höhna, S., Larget B., Liu, L., Suchard, M.a., Huelsenbeck, J.P., 2012. MrBayes 3.2: efficient Bayesian phylogenetic inference and model choice across a large model space. Syst. Biol. 61, 539-542. http://dx.doi.org/10.1093/sysbio/sys029.

Sass, C., Iles, W.J.D., Barrett, C.F., Smith, S.Y., Specht, C.D., 2016. Revisiting the Zingiberales: using multiplexed exon capture to resolve ancient and recent phylogenetic splits in a charismatic plant lineage. PeerJ 4, e1584. http://dx.doi. org/10.7717/peerj.1584.

Sass, C., Specht, C.D., 2010. Phylogenetic estimation of the core Bromelioids with an emphasis on the genus Aechmea (Bromeliaceae). Mol. Phylogenet. Evol. 55, 559571. http://dx.doi.org/10.1016/j.ympev.2010.01.005.

Shaw, J., Lickey, E.B., Schilling, E.E., Small, R.L., 2007. Comparison of whole chloroplast genome sequences to choose noncoding regions for phylogenetic studies in angiosperms: the tortoise and the hare III. Am. J. Bot. 94, $275-288$.

Shimodaira, H., 2002. An approximately unbiased test of phylogenetic tree selection. Syst. Biol. 51, 492-508. http://dx.doi.org/10.1080/ 10635150290069913.

Shimodaira, H., Hasegawa, M., 2001. CONSEL: for assessing the confidence of phylogenetic tree selection. Bioinformatics 17, 1246-1247.

Smith, S.Y., Benedict, J., Specht, C.D., Collinson, M.E., Leong-škorničková, J., Kvaček, J., Xiao, X., Fife, J., Marone, F., 2013. Reevaluation of the oldest fossils in Zingiberales and implications for inferring the evolutionary history of gingers, bananas, and relatives, in: Botany 2013 Abstracts. New Orleans, LA, p. 728.

Specht, C.D., Howarth, D.G., 2015. Adaptation in flower form: a comparative evodevo approach. New Phytol. 206, 74-90.

Stamatakis, A., 2014. RAxML version 8: A tool for phylogenetic analysis and postanalysis of large phylogenies. Bioinformatics 30, 1312-1313. http://dx.doi.org 10.1093/bioinformatics/btu033.

Stamatakis, A., 2006. Phylogenetic models of rate heterogeneity: a high performance computing perspective. In: Proceedings 20th IEEE International Parallel \& Distributed Processing Symposium. IEEE, p. 8. http://dx.doi.org/ 10.1109/IPDPS.2006.1639535.

Stamatakis, A., Hoover, P., Rougemont, J., 2008. A rapid bootstrap algorithm for the RAxML Web servers. Syst. Biol. 57, 758-771. http://dx.doi.org/10.1080/ 10635150802429642

Stanford, A.M., Harden, R., Parks, C.R., 2000. Phylogeny and biogeography of Juglans (Junglandaceae) based on matK and ITS sequence data. Am. J. Bot. 87, 872-882.

Stein, K., Rosche, C., Hirsch, H., Kindermann, A., Köhler, J., Hensen, I., 2014. The influence of forest fragmentation on clonal diversity and genetic structure in Heliconia angusta, an endemic understorey herb of the Brazilian Atlantic rain forest. J. Trop. Ecol. 30, 199-208. http://dx.doi.org/10.1017/ S0266467414000030.

Stiles, F.G., 1979. Notes on the natural history of Heliconia (Musaceae) in Costa Rica. Brenesia 15 (Suppl.), 151-180.

Strong, D.R., 1982. Harmonious coexistance of Hispine beetles on Heliconia in experimental and natural communities. Ecology 63, 1039-1049.

Strong, D.R., 1977. Rolled-leaf hispine beetles (Chrysomelidae) and their Zingiberales host plants in Middle America. Biotropica 9, 156-169.

Suárez-Montes, P., Fornoni, J., Núñez-Farfán, J., 2011. Conservation genetics of the endemic Mexican Heliconia uxpanapensis in the Los Tuxtlas tropical rain forest Biotropica 43, 114-121.

Taberlet, P., Gielly, L., Pautou, G., Bouvet, J., 1991. Universal primers for amplification of three non-coding regions of chloroplast DNA. Plant Mol. Biol 178, 1105-1109.

Taylor, J., White, S.A., 2007. Observations of hummingbird feeding behavior at flowers of Heliconia beckneri and H. tortuosa in southern Costa Rica. Ornitol. Neotrop. 18, 133-138.

Temeles, E.J., Kress, W.J., 2003. Adaptation in a plant-hummingbird association. Science 300, 630-633. http://dx.doi.org/10.1126/science.1080003.

Temeles, E.J., Newman, J.T., Newman, J.H., Cho, S.Y., Mazzotta, R., Kress, W.J., 2016 Pollinator competition as a driver of floral divergence: An experimental test. PLoS ONE 11, e0146431. http://dx.doi.org/10.1371/journal.pone.0146431.

Temeles, E.J., Pan, I.L., Brennan, J.L., Horwitt, J.N., 2000. Evidence for ecological causation of sexual dimorphism in a hummingbird. Science 289, 441-443.

ter Steege, H., Vaessen, R.W., Cárden, D., Sabatier, D., Antonelli, A., Mota, S., Oliveir, D., Pitman, N.C.A., Jørgensen, P.M., Salomão, R.P., 2016. The discovery of the Amazonian tree flora with an updated checklist of all known tree taxa. Sci. Rep. 6, 29549. http://dx.doi.org/10.1038/srep29549.

Thiers, B., 2012. Index Herbariorum: a global directory of public herbaria and associated staff. New York Bot. Gard. Virtual Herb. <http://sweetgum.nybg.org/ $\mathrm{ih} />$.

Tripp, E.A., McDade, L.A., 2013. Time-calibrated phylogenies of hummingbirds and hummingbird-pollinated plants reject a hypothesis of diffuse co-evolution. Aliso 31, 89-103.

Westerband, A.C., Horvitz, C.C., 2015. Interactions between plant size and canopy openness influence vital rates and life-history tradeoffs in two neotropical understory herbs. Am. J. Bot. 1, 1290-1299. http://dx.doi.org/10.3732/ ajb.1500041.

White, T.J., Bruns, T. Lee, S., Taylor, J., 1990. Amplification and direct sequencing of fungal ribosomal RNA genes for phylogenetics. In: Innis, M.A., Gelfand, D.H. Sninsky, J.J., White, T.J. (Eds.), PCR Protocols: A Guide to Methods and Applications. Academic Press, San Diego, pp. 315-322. 
Wright, S., 1934. An analysis of variability in number of digits in an inbred strain of guinea pigs. Genetics 19, 506-536.

Yang, Z., 2014. Molecular Evolution: A Statistical Approach. Oxford University Press, Oxford.

Yang, Z., 2007. PAML 4: phylogenetic analysis by maximum likelihood. Mol. Biol. Evol. 24, 1586-1591. http://dx.doi.org/10.1093/molbev/msm088.
Yang, Z., Rannala, B., 2014. Unguided species delimitation using DNA sequence data from multiple loci. Mol. Biol. Evol. 31, 3125-3135. http://dx.doi.org/ 10.1093/molbev/msu279.

Yang, Z., Rannala, B., 2006. Bayesian estimation of species divergence times under a molecular clock using multiple fossil calibrations with soft bounds. Mol. Biol. Evol. 23, 212-226. http://dx.doi.org/10.1093/molbev/msj024. 